\title{
Academic Uses of Video Games: A Qualitative Assessment of Research and Teaching Needs at a Large Research University
}

\author{
Shannon L. Farrell, Amy E. Neeser, and Carolyn \\ Bishoff $^{*}$
}

\begin{abstract}
Academic libraries develop collections and services for scholars who use video games in teaching and research. However, there are no assessments of related information and technology needs. The authors conducted 30 semistructured interviews to gather data about these needs and understand how the University of Minnesota Libraries can facilitate access to games and technology. A total of 28 interviewees used games in research, and 23 used games in teaching. We identified a variety of information and technology needs; many showed strong disciplinary trends. The findings can inform needs-based multidisciplinary strategies to develop video game services and collections relevant to unique academic communities.
\end{abstract}

\section{Introduction}

Recent studies show that video games are ingrained in American culture and, increasingly, higher education. A 2015 Pew Research Center survey found that 49 percent of American adults and 67 percent of adults ages 18-29 play video games. ${ }^{1}$ The New Media Consortium reported that games and gamification have several applications in higher education, as educational technology and components of blended learning. ${ }^{2}$ A search for "video games" in major article indices finds game technology used in diverse research areas.

College and research libraries share a vision of exceptional services to motivate and facilitate cutting-edge research and student learning ${ }^{3}$ and have proactively supported scholars using and experimenting with video games. Librarians frequently collaborate with faculty and students to create game collections and interactive spaces for research, teaching, game development, and play. Despite this, there are currently no multidisciplinary assessments that provide an overview of the information and technology needs required by scholars working with video games. Some disciplinary-specific

* Shannon L. Farrell is Natural Resources Librarian in the Natural Resources Library at the University of Minnesota Twin Cities; e-mail: sfarrell@umn.edu. Amy E. Neeser is Assistant Librarian, Library Research-Science and Engineering in the University Library at the University of Michigan, Ann Arbor; e-mail: aneeser@umich. edu. Carolyn Bishoff is Physics, Astronomy, and Earth Sciences Librarian in the Walter Library at the University of Minnesota Twin Cities; e-mail: bishoff@umn.edu). (C2017 Shannon L. Farrell, Amy E. Neeser, and Carolyn Bishoff, Attribution-NonCommercial (http://creativecommons.org/licenses/by-nc/4.0/) CC BY-NC. 
needs are understood, such as the needs of game design programs and curricula, but most information on needs is based on anecdotal evidence.

The University of Minnesota (UMN) is a large, doctoral-granting research university. The Twin Cities campus includes more than 4,000 faculty and 52,000 students, 16 colleges, and more than 300 research, education, and outreach centers and institutes. There is no video game design program or department, but there are a number of research faculty, teaching faculty, and students who use video games for academic purposes. To understand the diverse uses of video games across disciplines, we conducted semistructured narrative interviews of faculty, staff, and graduate students who use games or gaming technology in their work. This paper explores the information and technology needs of scholars who use video games on the UMN campus, similarities and differences by discipline, and how college and research libraries can incorporate disciplinary needs into a strategic approach to video game services and collections.

\section{Literature Review}

Many academic libraries recognize that scholars using video games for research and instruction have unique information and technology needs. In 2008, Smith ${ }^{4}$ called for a better understanding of game scholars' information needs, research methods, and types of materials they require, but there are three challenges to understanding those needs on a large scale: lack of information on conducting a comprehensive needs assessment of academic video game users, scarce information about research and teaching needs related to video games, and little information about how unique disciplinary or institutional needs affect a game-related collection or service.

Most library literature on games focuses on recommended genres and equipment $t^{5}$ or the specifics of acquiring, cataloging, and circulating games. ${ }^{6}$ Descriptions of video game collections and services often include a process to gather input; but none of these articles go into detail about the methods or findings, nor do they share a specific plan for how faculty and students would be consulted as technology, research, and classroom needs change.

Laskowski and Ward provide the most thorough overview of classroom and research needs and areas the library can support. ${ }^{7}$ They note three primary needs for game-related classes at the University of Illinois Urbana-Champaign (UIUC): access to labs with high-powered PCs, availability of course reserves, and access to discontinued games. They propose a variety of needs for game design classes and surmise that those classes would benefit from close liaison partnerships. The research needs they identify all relate to analyses of gameplay, and they propose archiving gameplay videos with player commentary. Since then, game technology has evolved and these recommendations are worth updating.

Many academic libraries have new game collections since the publication of these foundational articles, and descriptions of these collections provide the most up-to-date understanding of the evolving academic uses of video games. It is well recognized that researchers and instructors who use games come from many different disciplines, including education, economics, and the humanities. ${ }^{8}$ Some libraries developed partnerships with one department or discipline, such as education ${ }^{9}$ or the arts. ${ }^{10}$ Librarians managing the game collection at the University of Chicago (UChicago) intend to serve a wide population, from music to media studies to computer science. ${ }^{11}$ UChicago also has strong faculty advocates who identified many potential users on campus. ${ }^{12}$ Game collections at the University of Michigan ${ }^{13}$ and Carleton University ${ }^{14}$ likewise support a range of courses and research interests from the sciences to the humanities.

Despite the variety of potential users, there is less documentation about how a library game collection reflects the disciplinary or departmental information and technology 
needs at a particular institution. The information available shows a surprising amount of consistency across academic game collections: most libraries collect commercially successful games to play on consoles, such as the Playstation 3 or XBox 360 . UIUC, ${ }^{15}$ the University of Michigan, ${ }^{16}$ and the University of California Santa Cruz (UCSC) ${ }^{17}$ have vintage games and game systems available. Though personal computer (PC) games are recognized as an important genre to collect, ${ }^{18}$ it was difficult to determine if any academic libraries collected PC games or provided hardware to play them. Carleton University is one of the few that does. ${ }^{19}$

There are similarities among the themes of many game collections. Collections at Virginia Commonwealth University (VCU) ${ }^{20} \mathrm{UChicago}^{21}$ and the University of Michigan $^{22}$ all represent the history of video game development and the evolution of games through time. Many academic game collections also focus on acquiring current releases. $^{23}$

Some libraries have unique aspects to their collections. For example, VCU collects games specifically for users in the arts. The arts librarian looks for "games that have certain aesthetics ... have significant artistic direction, unique narrative or cerebral gameplay." ${ }^{24}$ Some libraries plan to expand beyond console games, including UChicago; a faculty member from English hopes that "computer and mobile games" are eventually added to the collection. ${ }^{25}$ At least two libraries make game development software available: the University of Calgary game resources include "six high performance (liquid cooled) gaming PCs" with software packages including Unity and several Autodesk products; ${ }^{26}$ and Carleton University had requests for software including Poser Pro. ${ }^{27}$

As affordable game technology evolves, libraries take steps to stay up-to-date with new research and teaching applications. Commonly, academic libraries rely on subject librarians to stay aware of research and instruction trends, and that is no different when video games are involved. ${ }^{28}$ Another strategy involves direct faculty and student input, which often happens during the initial development of video game collections. ${ }^{29}$ However, some collections are built from donations and gifts like at the University of Calgary; ${ }^{30}$ a for those, the relationship between the collection and local research and teaching needs is less clear. Some collections accept donations for a particular purpose: the University of Michigan Computer and Video Game Archive (CVGA) accepts donations and purchases games to create the most comprehensive collection possible, while also collecting in targeted ways to support faculty and student activities. ${ }^{31}$

No literature to date provides a comprehensive overview of the information and technology needs of academic video game users. Many universities rely on a handful of faculty advisors to understand needs on campus; UIUC consulted a faculty member and hosted a game night for students to gather input,;2 Carleton University similarly "crowd-sourced" input for their game collection from faculty, students, and library staff, though they did not describe their methods. ${ }^{33}$ At UChicago, faculty advocates assisted directly with the development of the collection. ${ }^{34}$ The University of Michigan LibGuide for the CVGA provides the most comprehensive list of courses, research, and faculty who have used the CVGA on their campus, but the list is intended to inform students and potential users, not provide an overview of trends about research and teaching needs or inform collection and service development. ${ }^{35}$

\section{Methods}

This paper explores the information and technology needs of games scholars at UMN Twin Cities and how libraries can accommodate disciplinary needs and help overcome barriers to academic work related to video games.

We formulated the following research questions:

1. Which disciplines are represented among UMN scholars who use video games? 
2. Do UMN scholars who use video games collaborate outside their disciplines?

3. What are the information and technology needs for game-related research and teaching at UMN?

4. Are there similarities in the information and technology needs of researchers and instructors using video games, despite disciplinary differences?

5. If obstacles are identified, how can libraries help researchers and instructors overcome them and enhance their work?

To answer these questions, we identified scholars at UMN who work with video games or video game technology. This was defined broadly and ranged from using games as an object of study to using the technology to study a separate problem. We excluded researchers studying "game theory" (a mathematical concept) or studying analog games such as board games or logic puzzles because our interest was in needs related to video game technology.

We used a number of methods to identify a population of faculty, staff, and students. SciVal Experts, a research profile system used at UMN, identified 62 people who had published on video games. The SciVal Experts system does not include all UMN scholars, and the database best represents disciplines that use journal articles as their primary means of scholarly communication, so we also conducted searches of the UMN website to find mentions of video games in biographies, research statements, or classes. Word-of-mouth also played an important role: we asked librarians at the UMN for recommendations and used snowball sampling to find additional names from those we interviewed. Through these combined methods, we obtained 92 total names, which we considered an exhaustive list.

A qualitative approach was most appropriate, as opposed to a survey, since it allowed participants to drive the conversation and focus on topics important to them. Since we did not have personal connections to those doing video game-related work at $\mathrm{UMN}$, interviews had the additional advantage of building new relationships. We sent invitations to conduct hour-long, semistructured interviews to our sample of faculty, staff, and graduate students. Those who responded were interviewed at a location of their choice. Those who did not respond were sent a follow-up invitation two weeks later. Of the 92 names in the original population, 30 people agreed to be interviewed, 20 declined, and 42 did not respond.

Each interview was attended by two members of the research team and was audio recorded with the interviewee's permission. We asked guiding questions, but the interviewee led the conversation. Instead of transcribing each interview, we used a Google form to code data from the audio (see appendix for codes and definitions). We used a controlled vocabulary to code most topics and captured quotes and observations with free-text responses. To make sure that different coders maintained a level of consistency, we reviewed the audio from the first 15 interviews in tandem and resolved disputes with the codes and analysis methodology. We then assigned a single reviewer to the final 15 subjects.

We took measures to ensure participants' anonymity by assigning each participant a random number, coding participants by discipline instead of department, and using generic titles (such as untenured faculty) in place of official positions. These methods were approved by the UMN Institutional Review Board on October 17, 2014.

\section{Results}

We identified 92 people from four broad disciplinary groups: arts and humanities, social sciences, science/technology/engineering/math (STEM), and health sciences (see table 1). We interviewed 30 people from this population, an overall response rate of 33 percent. The interview sample overrepresented the STEM population, which had a 52 
percent response rate, and underrepresented health sciences, which had a 19 percent response rate (see figure 1). It also overrepresented graduate students, who had a 46 percent response rate overall. Participants were split almost evenly between graduate students (13) and faculty/staff (17). It was also noteworthy that the largest number of interviewed graduate students (in both frequency and percentage of total) occurred in arts and humanities (5).

\section{TABLE 1}

Demographics of Interview Subjects (Sample) and Subject Population by Discipline and Academic Status

\begin{tabular}{|l|c|c|c|c|c|c|c|c|}
\hline \multirow{2}{*}{ Discipline } & \multicolumn{2}{|c|}{ Graduate Students } & \multicolumn{2}{|c|}{ Tenured Faculty } & \multicolumn{2}{c|}{$\begin{array}{c}\text { Untenured Faculty } \\
\text { \& Staff }\end{array}$} & \multicolumn{2}{c|}{ Grand Total } \\
\cline { 2 - 9 } & Sample & Population & Sample & Population & Sample & Population & Sample & Population \\
\hline $\begin{array}{l}\text { Arts \& } \\
\text { Humanities }\end{array}$ & 5 & 9 & 1 & 4 & 1 & 4 & 7 & 17 \\
\hline $\begin{array}{l}\text { Social } \\
\text { Sciences }\end{array}$ & 3 & 7 & 4 & 13 & 0 & 7 & 7 & 27 \\
\hline STEM & 4 & 5 & 3 & 11 & 4 & 5 & 11 & 21 \\
\hline $\begin{array}{l}\text { Health } \\
\text { Sciences }\end{array}$ & 1 & 7 & 3 & 14 & 1 & 6 & 5 & 27 \\
\hline Total & $\mathbf{1 3}$ & $\mathbf{2 8}$ & $\mathbf{1 1}$ & $\mathbf{4 2}$ & $\mathbf{6}$ & $\mathbf{2 2}$ & $\mathbf{3 0}$ & $\mathbf{9 2}$ \\
\hline
\end{tabular}

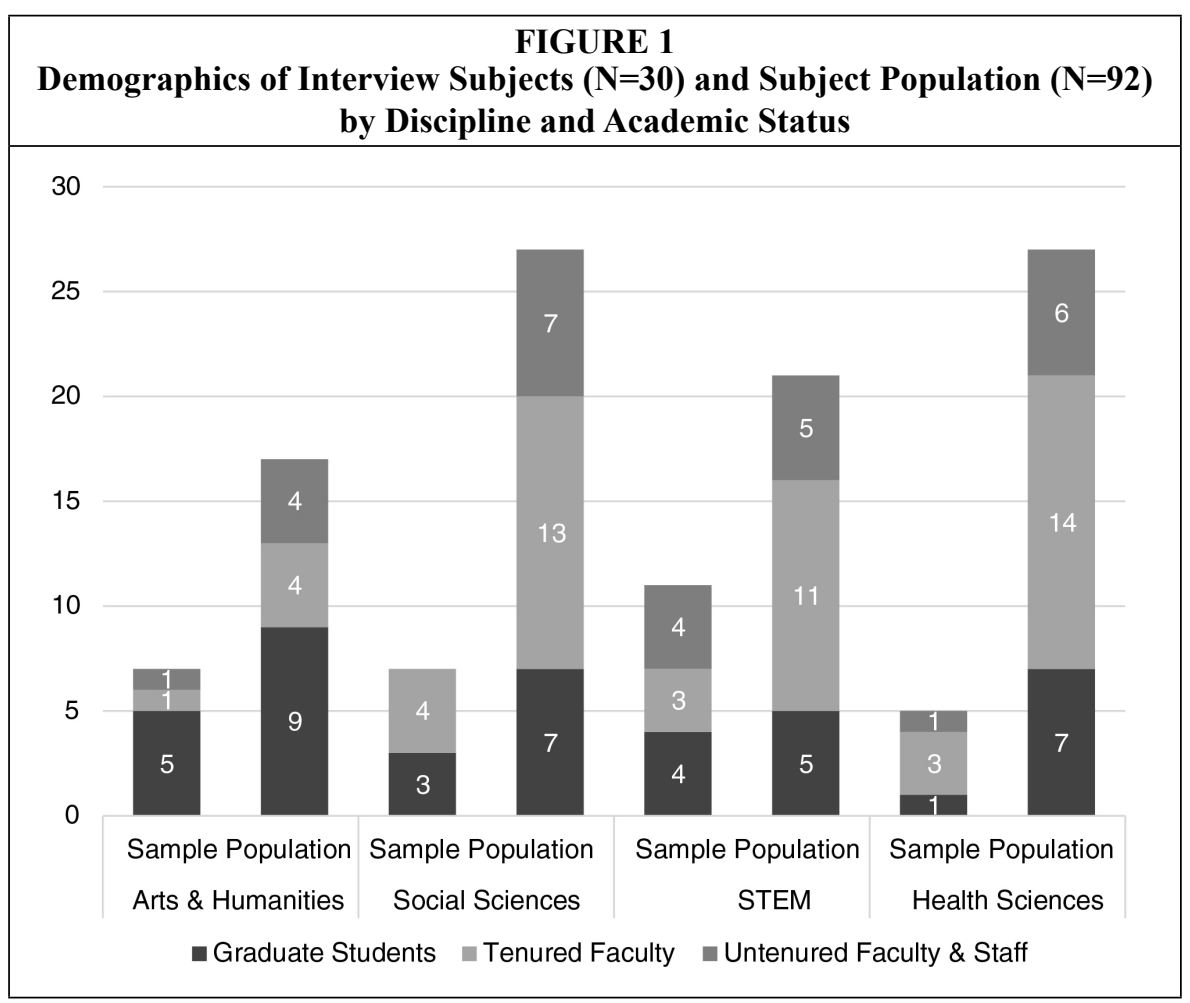


Interdepartmental collaboration was defined as a relationship, formal or informal, between an interview participant and a member of another department. Both formal and informal collaboration were considered: formal collaboration was defined as a relationship based on an externally recognized partnership, such as a project, grant, coauthorship on a manuscript, or serving as an academic advisor or dissertation committee member; informal collaboration was defined as unofficial or casual partnerships based on consultations, conversations, and friendships that contribute to academic work. These data were used to determine whether an interviewee's work was confined to a single department or discipline or whether he or she had potential connections outside the interviewee's home department. We found high levels of interdepartmental collaboration in all disciplines (see figure 2). One third of interview participants (10) reported three or more interdepartmental relationships, including an untenured instructor in arts and humanities who collaborated with faculty and students across five different departments in arts and humanities, STEM, and social sciences. A total of 20 percent of participants (6) reported no collaboration or no collaboration outside their departments, including an untenured instructor in STEM who only collaborated with graduate teaching assistants in his department. Interviewees from arts and humanities were the only group where all interviewees reported collaborative partnerships.

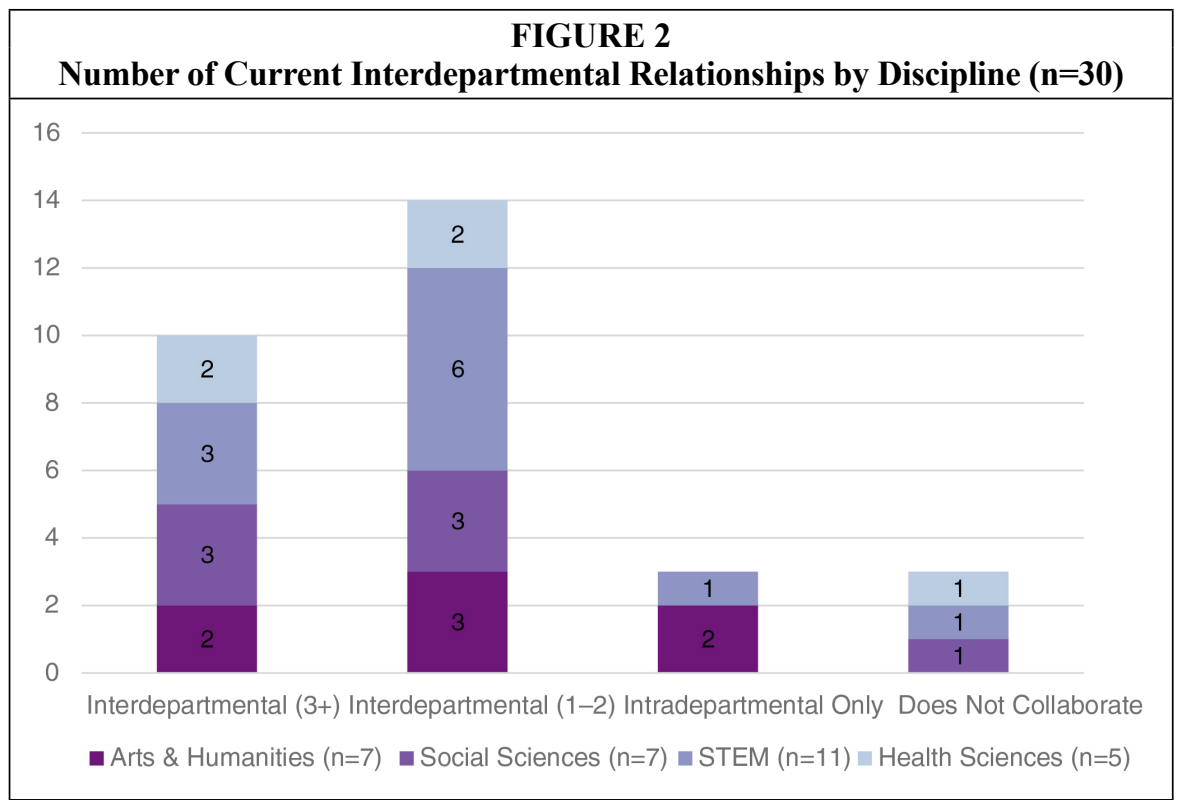

The majority (21/30) of interview participants used video games in both research and teaching (see figure 3). Most participants conducted research with video games (28/30). About a quarter of interviewees (7), most from STEM and health sciences, used games solely in research, including a graduate student in STEM who received funding for research and did not teach. Five categories of game-related research emerged from the interviews (see figure 4). Interviewees who conducted research on the development of games or technology typically produced software or algorithms that could be used in games or developed games based on existing technology. Researchers who used games as instrumentation modified game technology to collect quantitative 
data or used video games as a cheaper alternative to another analogous instrument they could have purchased. When games were used as an object of study, researchers often applied critical analysis or theory to a video game as they would another text or primary source. When games were used to study influences on people or society, the researcher typically used qualitative methods to examine some societal impact of games. Finally, games were studied by some for their educational applications and impact on student outcomes. Some interviewees used games in more than one way, such as a graduate student in arts and humanities who studied video games as both a cultural object and a cultural influence. Similarly, an untenured faculty in STEM researched video games as an educational technology while also examining their social influence. Each discipline was represented in 3-4 research application categories. At the same time, strong disciplinary research trends were present and each category was dominated by a single discipline, with the exception of educational technology. Educational technology applications primarily included testing games and game-based learning principles in the classroom.

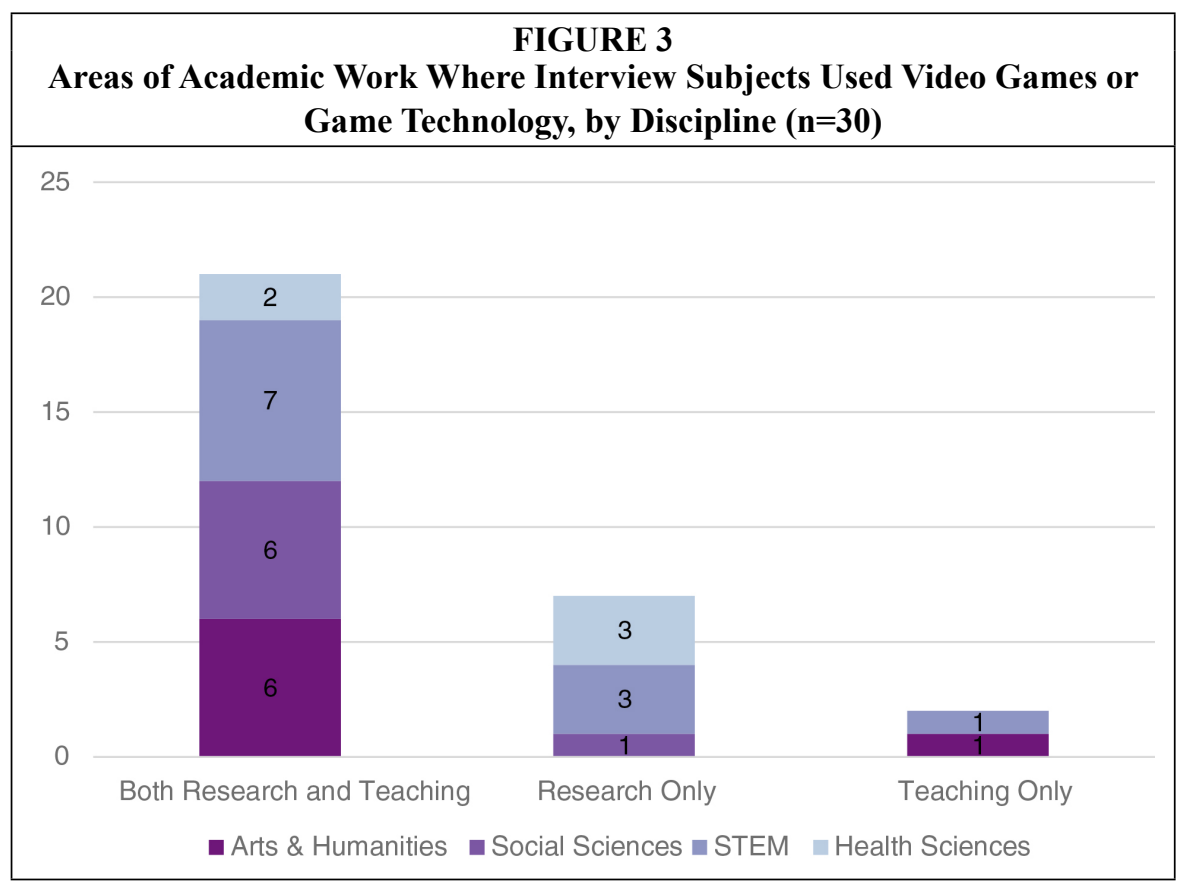

Fewer people used video games in teaching (23/30) than in research, but interviewees who taught with games most often used them in research as well. For example, a tenured faculty researched the effectiveness of a mobile game to create and grade assignments and used the same game in several of his courses. Only two individuals used video games solely in a teaching capacity, including an instructor in STEM who had no research responsibilities. Four categories of teaching applications emerged from the interviews (see figure 5). Some instructors designed games from scratch for students to use in the classroom. Other instructors taught game design principles sometimes using commercial games and sometimes requiring students to create their own games. Games were also used as course material, analogous to texts or other primary sources: instructors assigned games in the syllabus or had students watch videos of 


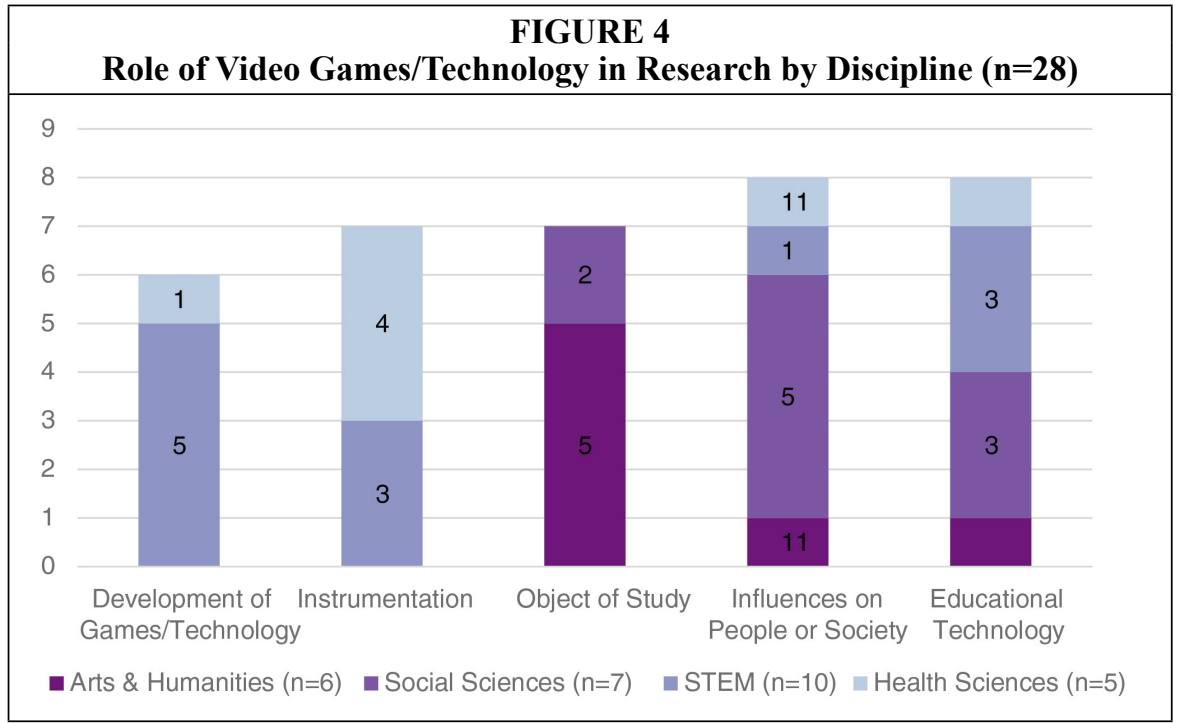

others playing through a game. Finally, instructors discussed games, game mechanics, or their own research on games in the classroom but may not have assigned games to students to play in the course. Similar to research applications, some interviewees used games in the classroom multiple ways, like an untenured faculty in STEM who taught game design and also used video games as course material. Every disciplinary group used video games as course material and as a discussion piece in class. Some teaching applications were more common in particular disciplines; 4 of 8 STEM interviewees designed a game for their classes and 5 of 6 from the social sciences used games as course material. Overall, disciplinary trends were far less distinct. Table 2 summarizes the data from figures 3-5.

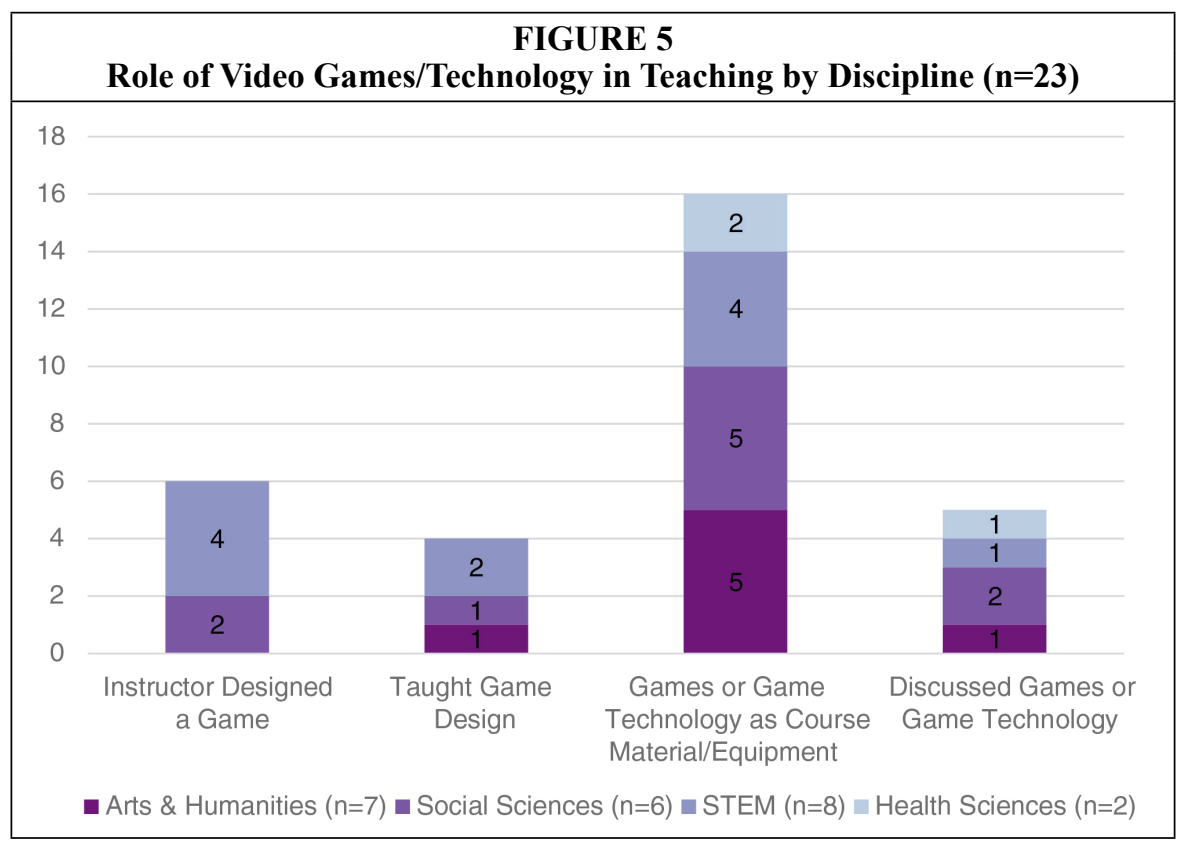


Academic Uses of Video Games 683

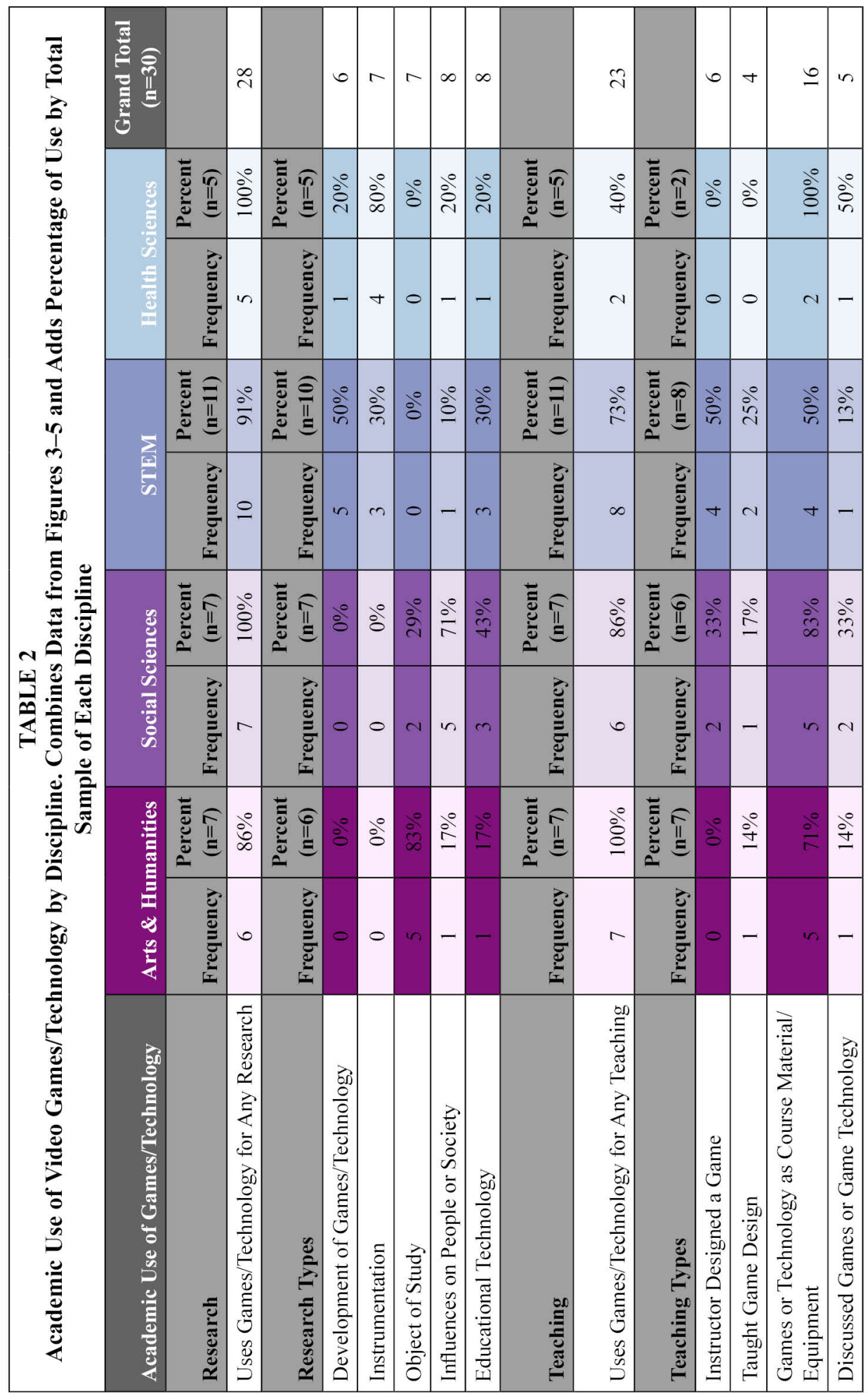




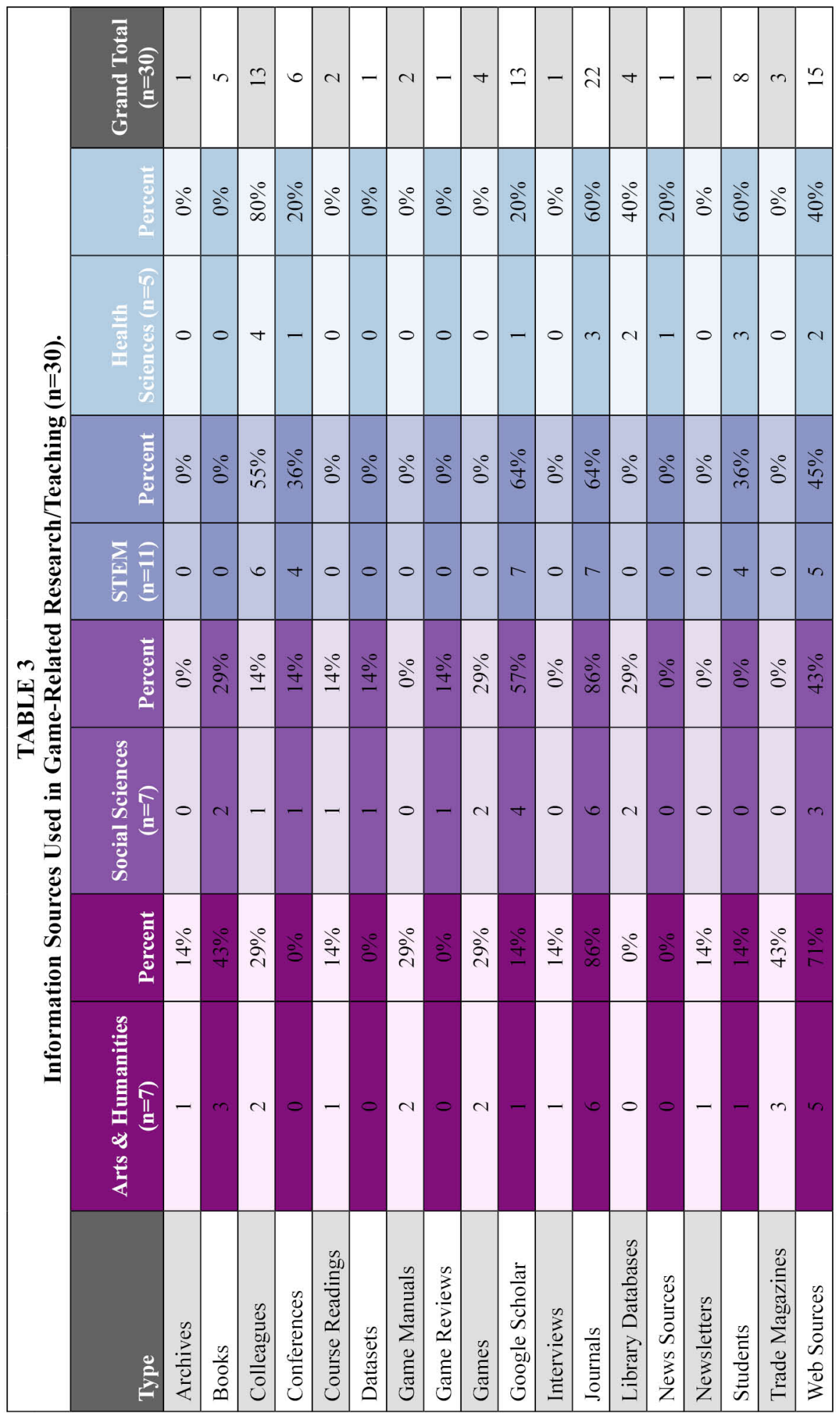


Among the interviewees, 18 types of information were used (see table 3). Arts and humanities participants used the most information sources (13), while STEM participants used the least (6). Video games were used as primary sources by interviewees in arts and humanities and social sciences, including a tenured faculty in the social sciences who studies game symbology. Interviewees from all disciplines used colleagues, web sources, journals and Google Scholar. Dominant information sources emerged from each discipline: arts and humanities, journals and web sources (see figure 6); social sciences, journals (see figure 7); STEM, colleagues, journals, and Google Scholar (see figure 8); and health sciences, colleagues (see figure 9).

Participants identified 17 unique technology needs (see table 4). The following technology categories emerged: equipment, games, programming languages, servers, software, and web applications. Equipment included any type of hardware, from game consoles like Xbox or PlayStations, to mobile phones or personal computers (PCs). PCs were the most common piece of equipment identified as required by the whole sample, but peripherals (accessories such as game controllers) were the predominant type of equipment mentioned by participants in the health sciences. For example, a Wii balance board was used to study involuntary bodily movements. Only five interviewees used console system equipment (see figure 10).

Games referred to all types of playable software, and four categories of video games emerged: PC games, played on a computer and often accessed through a platform like Steam, were the most common, followed by console games (played on a console) and web games (played through an Internet browser); mobile games (played on a phone) were the least common. Arts and humanities and social sciences participants had the strongest need for games, and they use the widest variety of platforms. For example, a graduate student in arts and humanities uses PC, console, and mobile games to study

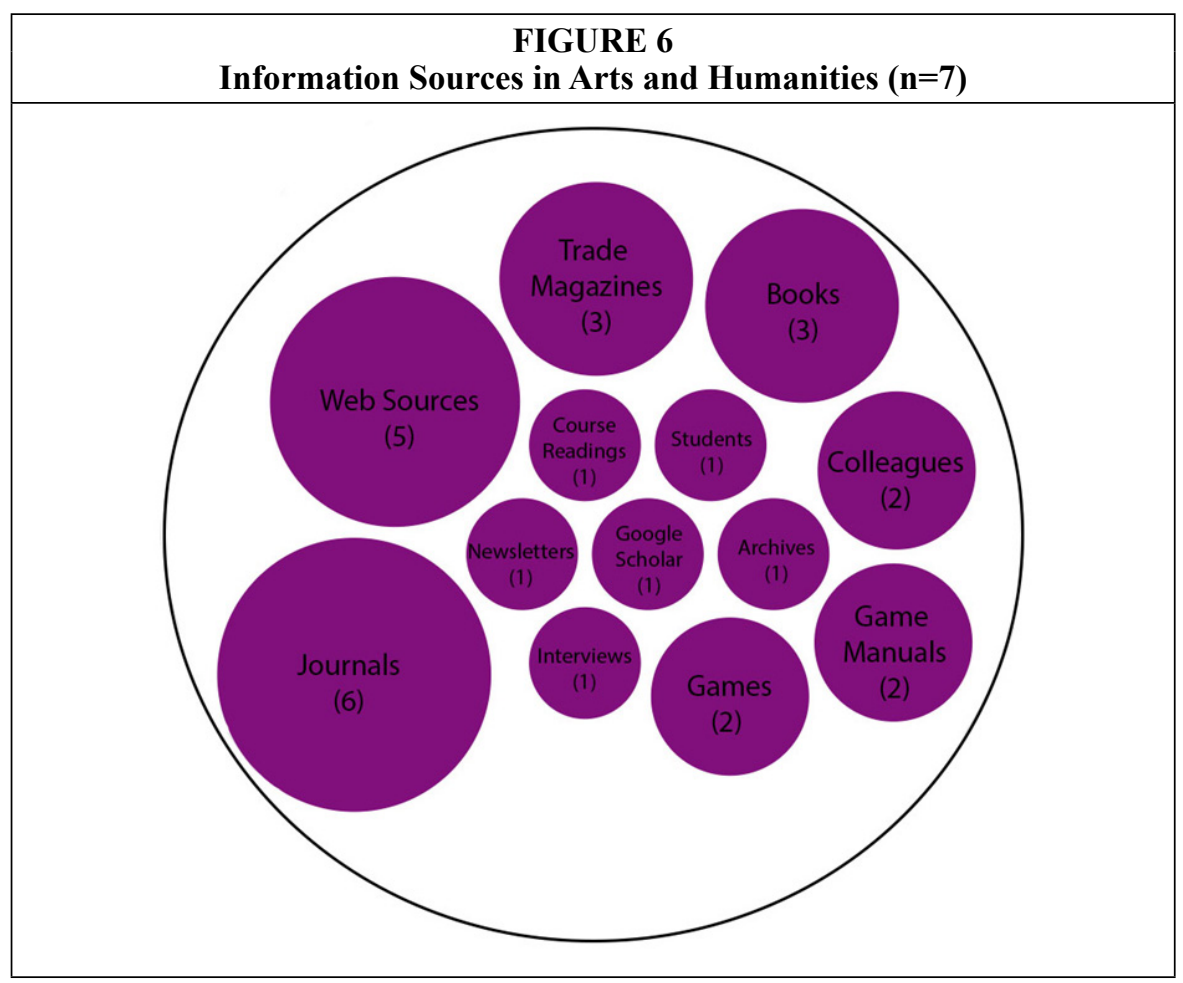



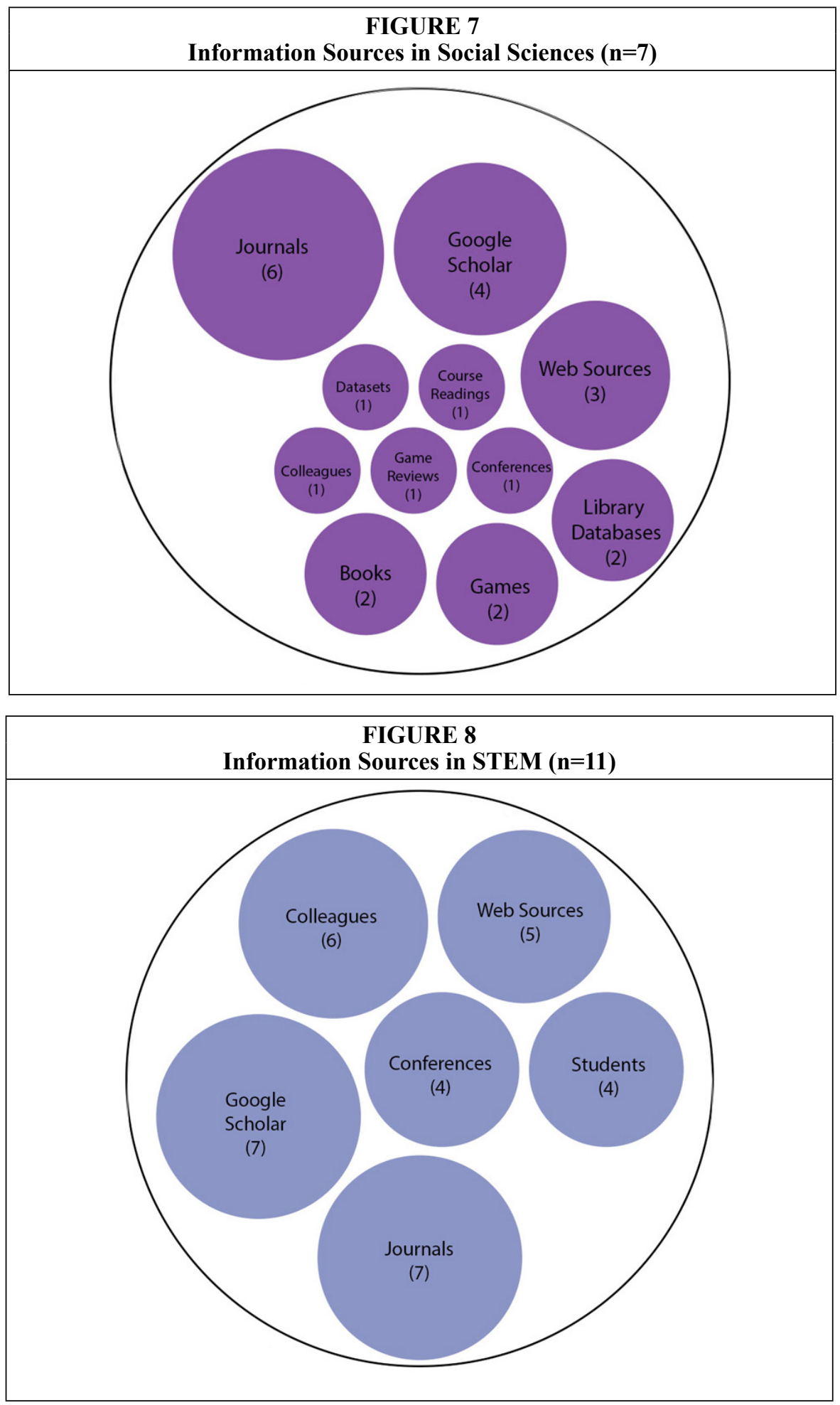


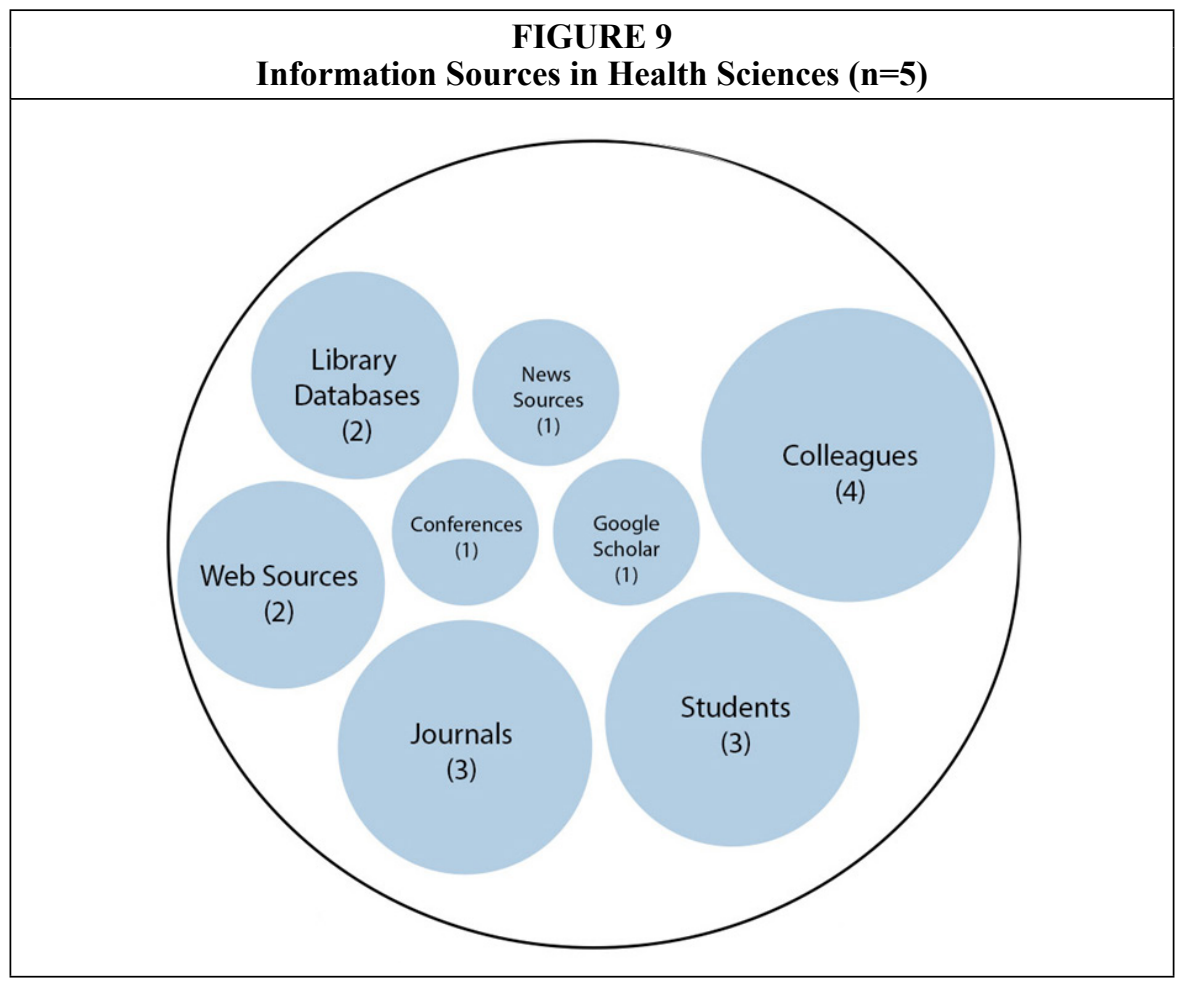

music, and a graduate student in the social sciences uses web, PC, and console games to study representations of bodies. Social sciences have the largest use of web-based games, used by 3 of 4 interviewees. Only 1 of 11 STEM participants used video games in his or her academic activities (see figure 11), a graduate student studying a prominent massively multiplayer online role-playing game (MMORPG).

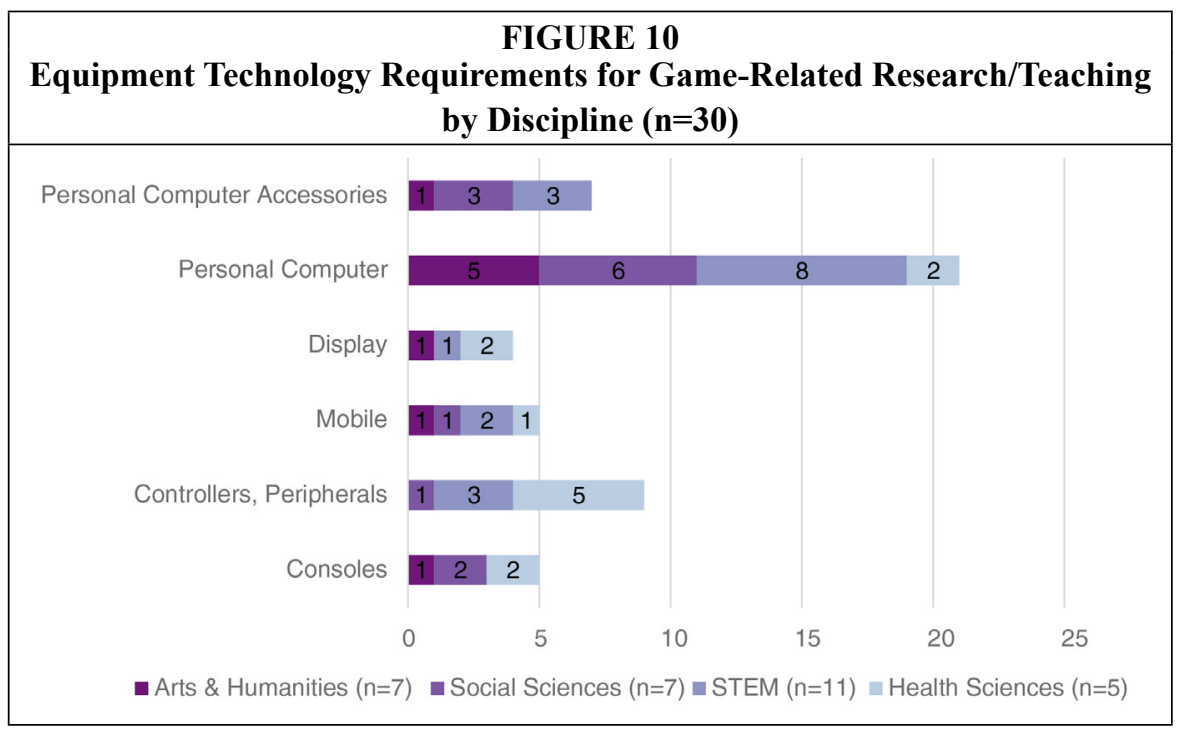




\begin{tabular}{|c|c|c|c|c|c|c|c|c|c|c|c|c|c|c|c|c|c|c|}
\hline & 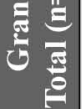 & in & $a$ & in & $\nabla$ & $\vec{\sim}$ & $\curvearrowright$ & $\nabla$ & & in & $N$ & $m$ & $\mathrm{~N}$ & $r$ & $\infty$ & $\mathrm{N}$ & $r$ & $\nabla$ \\
\hline & $\begin{array}{l}5 \\
8 \\
8\end{array}$ & ஓे & 용 & 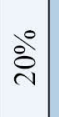 & ஓे & ஓे & $\dot{\delta}^{\circ}$ & ठ̊ & தீ & 号 & ठें & ஃें & oे $^{\circ}$ & 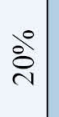 & ठें & $\stackrel{\text { ڤे }}{\mathrm{d}}$ & ठें & \&̊ \\
\hline ஜิ & 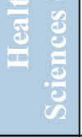 & $N$ & in & - & $\sim$ & $N$ & 0 & 0 & 0 & $\sim$ & - & 0 & 0 & - & - & - & - & 0 \\
\hline & 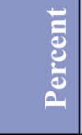 & $\dot{\delta}^{\circ}$ & 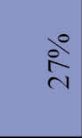 & $\begin{array}{l}\stackrel{0}{ } \\
\infty\end{array}$ & ஃ̊ & $\stackrel{\circ}{\stackrel{0}{r}}$ & 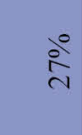 & தे & $\check{a}^{\circ}$ & $\stackrel{\circ}{0}$ & ठे & 离 & ถั & 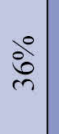 & in & ठ̊ & $\stackrel{\stackrel{\circ}{ }}{+}$ & ถे \\
\hline 矛 & $\sum_{\frac{1}{2}}=$ & 0 & $m$ & $N$ & - & $\infty$ & $m$ & 0 & - & 0 & 0 & $m$ & - & $\nabla$ & 0 & - & in & - \\
\hline 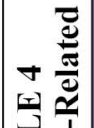 & 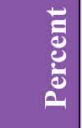 & $\stackrel{\text { ڤे }}{\circ}$ & $\stackrel{\stackrel{\circ}{ \pm}}{ }$ & 送 & ठ̊ & ஓं & 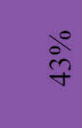 & $\stackrel{\circ}{\stackrel{\circ}{\sigma}}$ & $\stackrel{\circ}{i}$ & ڤัँ & $\dot{\delta}^{\circ}$ & ठ̊ & 巳̊ & $\stackrel{\circ}{\stackrel{\circ}{I}}$ & $\stackrel{\circ}{\stackrel{\Xi}{ \pm}}$ & ठ & ஓ̊ & ڤे \\
\hline 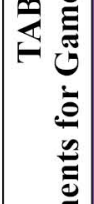 & 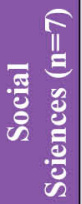 & $\mathrm{N}$ & - & - & 0 & 0 & $m$ & $m$ & $\nabla$ & $\sim$ & 0 & 0 & - & - & - & 0 & - & d \\
\hline 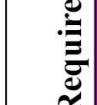 & 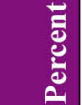 & $\stackrel{\stackrel{\circ}{ \pm}}{\square}$ & & $\stackrel{\circ}{\stackrel{\circ}{ \pm}}$ & 送 & $\frac{\circ}{\pi}$ & $\stackrel{\circ}{\text { dे }}$ & $\stackrel{\stackrel{\circ}{ \pm}}{ }$ & & $\stackrel{\circ}{\dot{I}}$ & $\stackrel{\text { İ }}{ \pm}$ & தें & $\delta^{\circ}$ & $\stackrel{\circ}{ \pm}$ & हें & $\mathrm{g}^{\circ}$ & $8^{\circ}$ & $\stackrel{\circ}{\stackrel{ }{ \pm}}$ \\
\hline 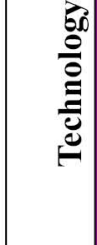 & 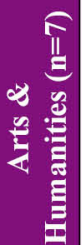 & - & 0 & - & - & in & - & - & in & - & - & 0 & 0 & - & 0 & 0 & 0 & - \\
\hline & 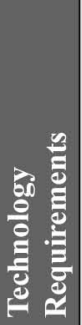 & 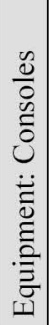 & 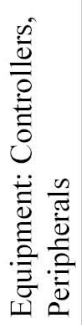 & 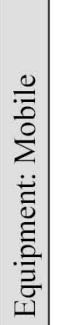 & 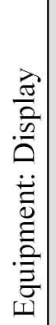 & 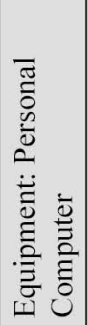 & 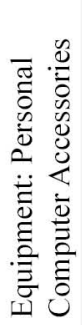 & $\begin{array}{l}00 \\
\ddot{3} \\
\ddot{\Xi} \\
\stackrel{\Xi}{0}\end{array}$ & 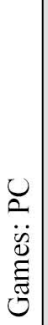 & 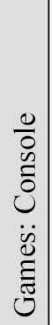 & 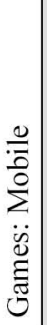 & 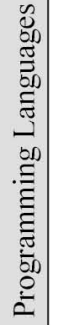 & 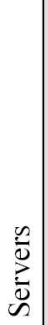 & 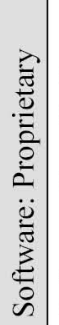 & 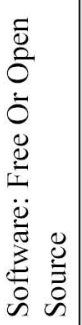 & 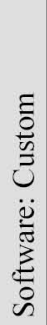 & 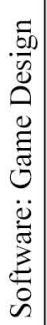 & 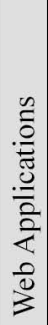 \\
\hline
\end{tabular}


Software as a category excluded video games but included almost any other type of digital application that a researcher or instructor identified as necessary to his or her work. The subcategories were chosen with collection development needs in mind; proprietary software would likely come at a cost and include access restrictions, while open source software would be more accessible for any library or user to install. Other categories of interest included custom software, which was usually designed by the researcher or instructor and might not be widely shared or available, and game design software. Game design software might overlap with one of the other categories: some interviewees used Unity, an open source game design software; some used the Unreal engine, which at the time of the interviews cost money to download and was not open source; and some built custom game design software of their own. STEM participants had the most software needs overall; and, as a group, both STEM and health

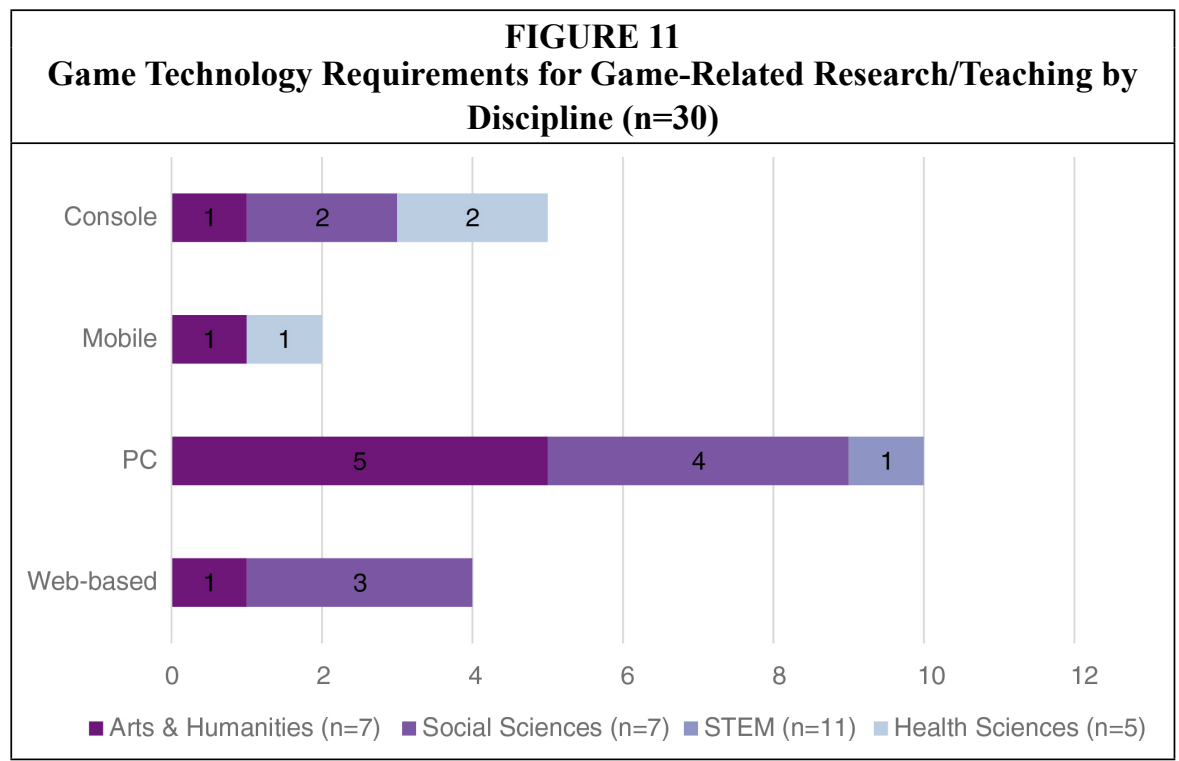

\begin{tabular}{|c|}
\hline FIGURE 12 \\
Software Technology Requirements for Game-Related Research/Teaching by \\
Discipline $(\mathrm{n}=\mathbf{3 0})$
\end{tabular}

\begin{tabular}{|r|r|r|r|r|}
\hline \\
Proprietary
\end{tabular}


sciences interviewees reported using some type of software from every category (see figure 12). However, the needs were diverse among individuals: a graduate student in STEM used proprietary robotics software and a tenured faculty member in STEM used open source software to teach programming. Arts and humanities interviewees overall did not report many software needs; only 1 of 7 interviewees described any software needs at all. However, members of every disciplinary grouping did report a need for proprietary software.

Some technology used by the interviewees in this study was free or provided by the university, like a personal computer, but many technology needs required some financial resources to fulfill. To determine how interviewees currently met their technology needs, we asked about the specific methods they used to acquire technology. We split the results on technology acquisition into two categories: graduate students and faculty/staff (see figures 13 and 14). Tenured and untenured faculty and staff were combined because the methods of technology acquisition were very similar for both groups. Graduate students used many strategies to acquire technology, including borrowing from others or using their own personal property. For example, one graduate student in the social sciences used free technology, borrowed games from others, made purchases, and still did not have all the technology he needed. On the other hand, faculty and staff primarily purchase technology. One faculty member in health sciences said, "I usually have a couple thousand bucks in my ICR [indirect cost recovery] account... that's more than enough to pay for the kinds of things we've been talking about [plasma screen, Xbox 360, games]." This trend holds true regardless of tenure status. Faculty and staff in STEM are using more freely available technology when compared to the other disciplinary groups. If the faculty, staff, or students had not yet acquired the technology they planned to use, those responses appear as "other." Faculty planned to either create the technology themselves or hire someone to create it, while graduate students were still considering their options.

Funding sources differed significantly by status, and untenured faculty and staff are shown separately from tenured faculty and graduate students (see figures 15-17). In general, graduate students and untenured faculty and staff relied on a variety of methods for funding compared to tenured faculty. In arts and humanities and social

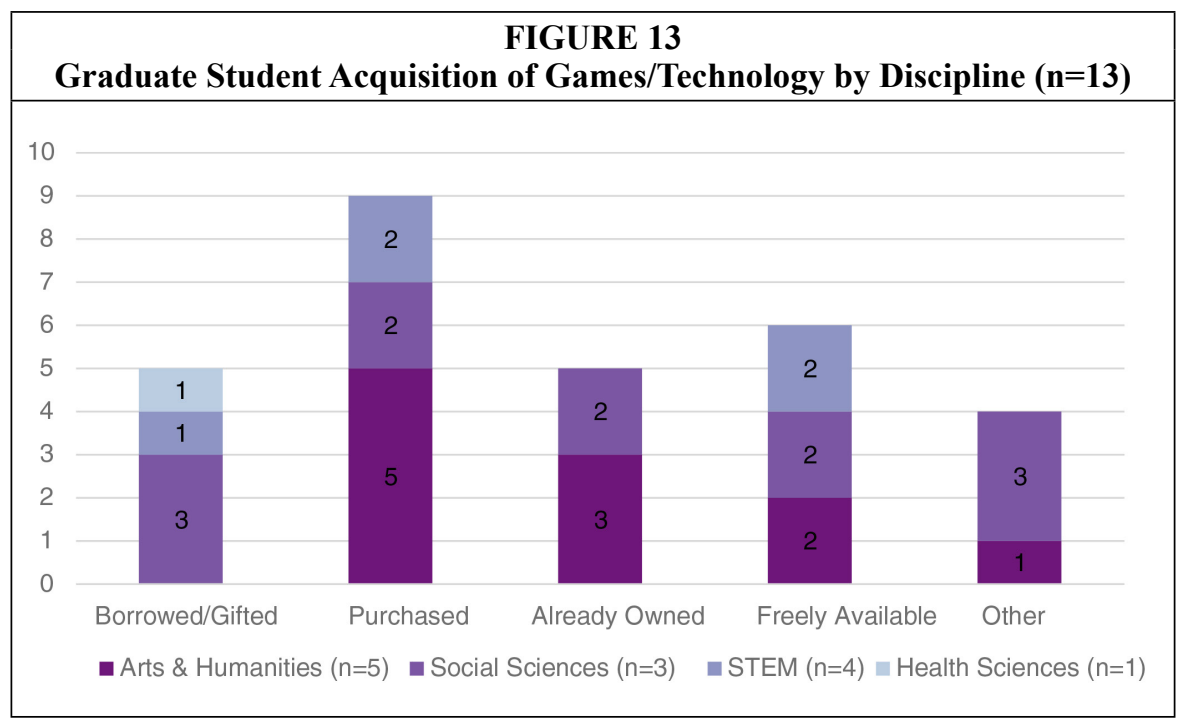



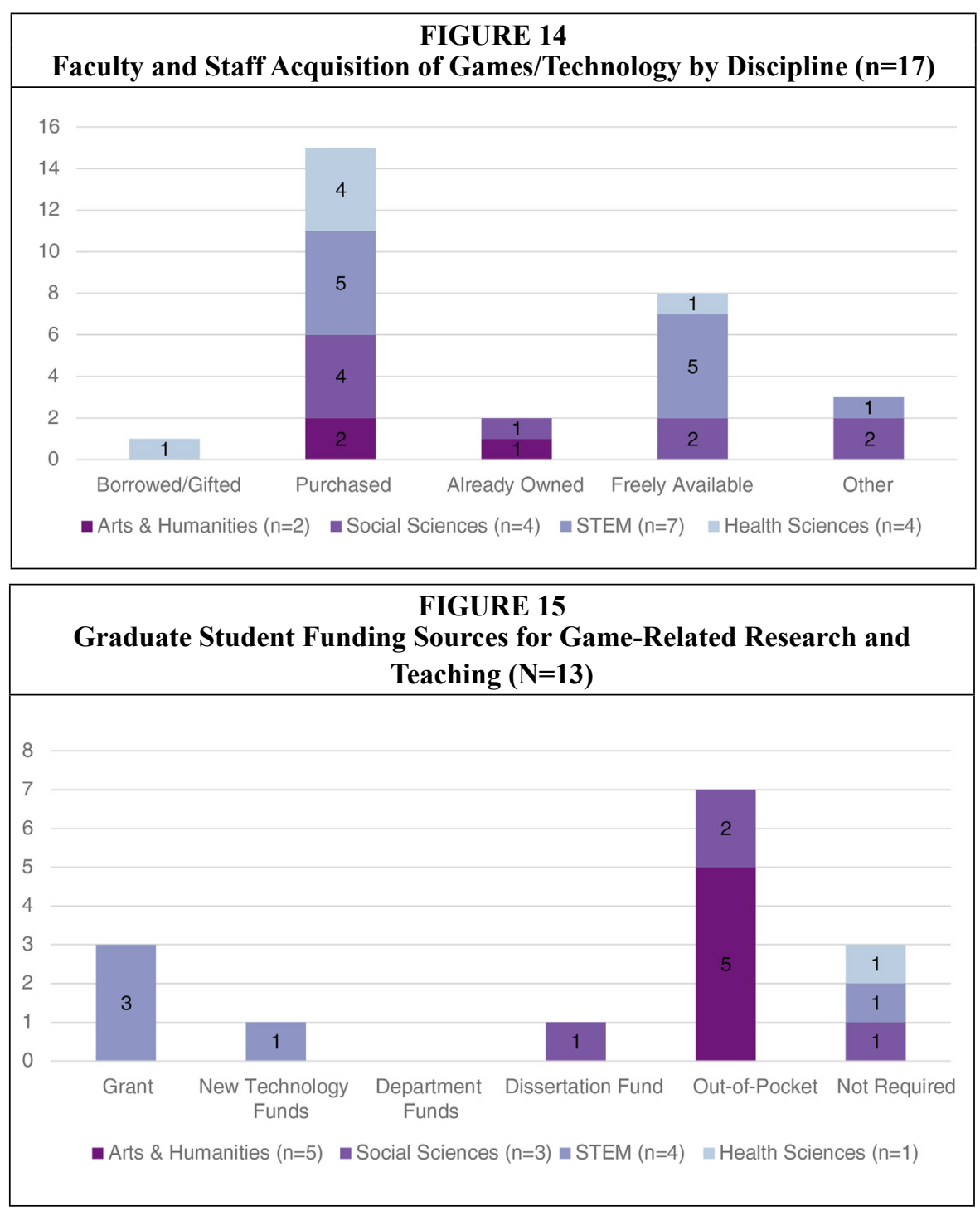

sciences, many graduate students paid out-of-pocket, such as a graduate student in arts and humanities who was unable to get funding for game skins (armor, clothing, and the like), which were required for his dissertation research. In STEM, graduate students received some funding from grants, but that was not the case for graduate students from other disciplines (see figure 15). Tenured faculty mostly got their funding from grants (10 out of 11 in our sample), with some additional support from ICR funds, departmental funds (funding providing by a researcher's or instructor's department), and new technology funds (funds provided by the department, college, or university to acquire technology) (see figure 16). Unlike graduate students, tenured faculty did not pay out-of-pocket costs. Health sciences' tenured faculty illustrated a depth of funding sources. Although there were only three participants in our sample, they had six sources of funding. One example is a tenured faculty member who had both an external grant and used department funding. Untenured faculty and staff ap- 

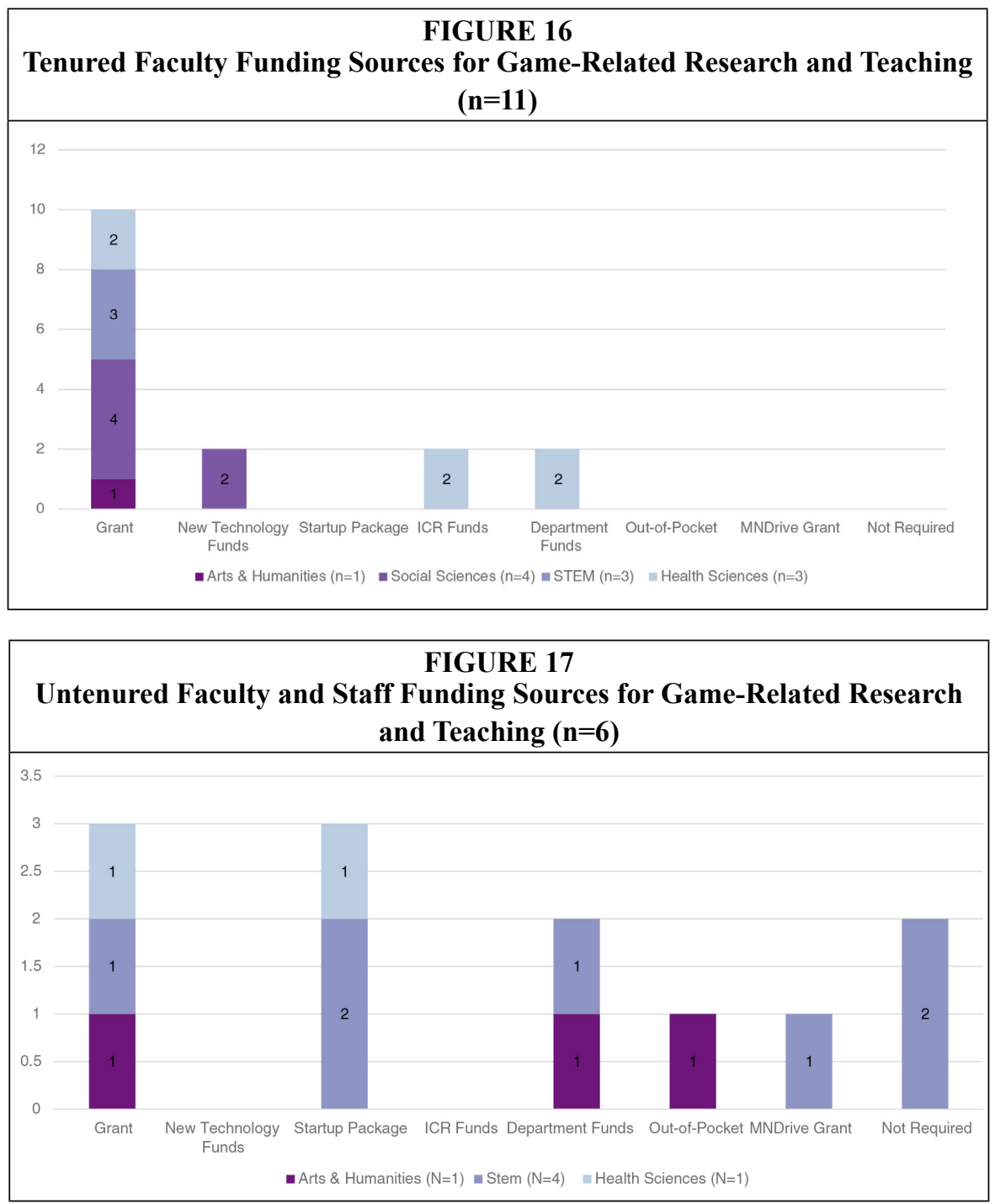

pear to be seeking multiple sources of funding (see figure 17). For example, in arts and humanities, an untenured instructor was funding his work with a grant, departmental funds, and his own money. Figures 18-21 summarize the data from figures 13-17 and organize it by discipline.

\section{Discussion}

\section{Research Limitations}

This research had several limitations. If an eligible participant did not mention his or her work with video games on a staff profile page or in publications, or if the participant was not located through recommendations or snowball sampling, he or she was not included among the population of $92 \mathrm{UMN}$ game scholars. The interview data was more limited in scope because some eligible participants were away on sabbatical, did not respond to invitations, or declined an interview. 

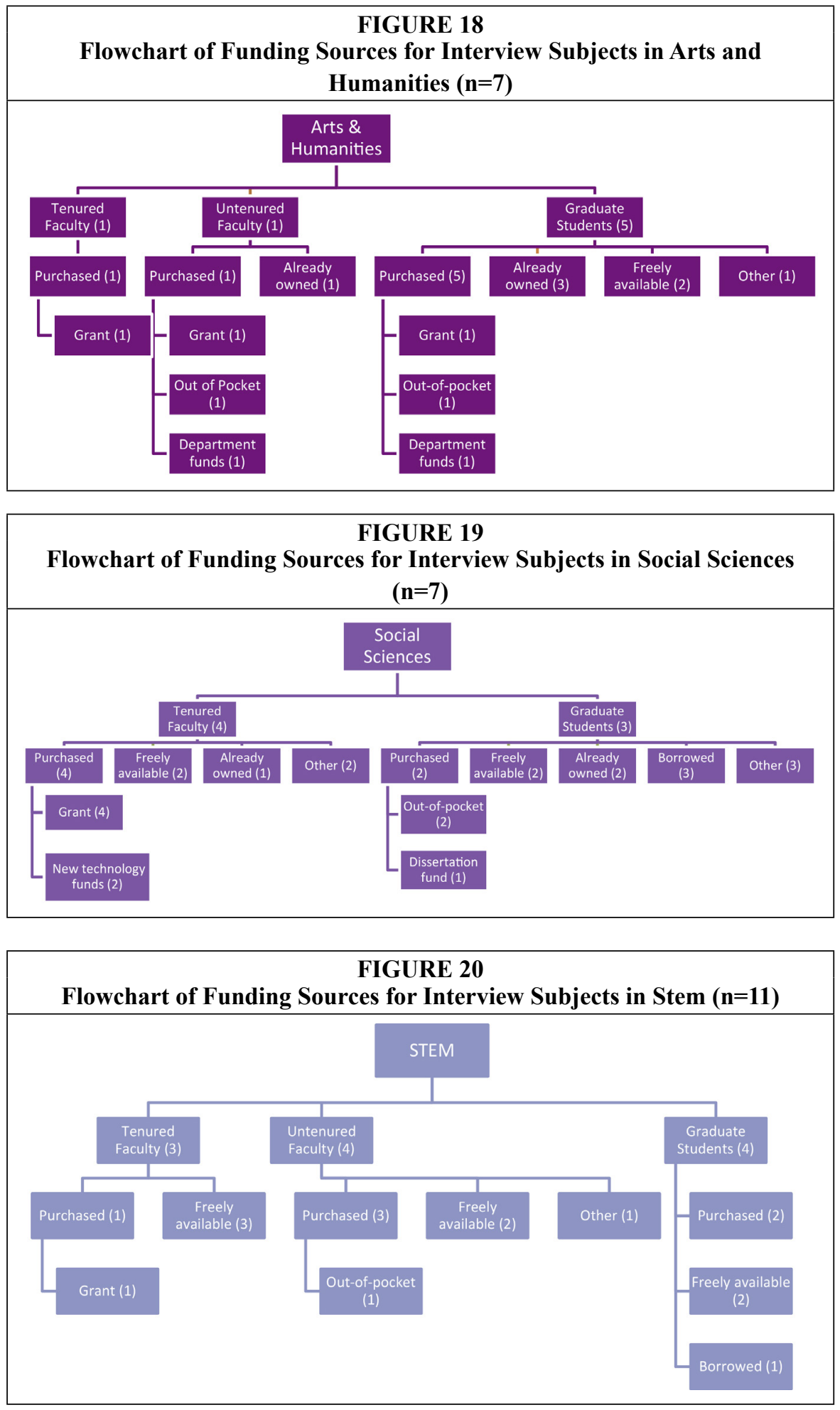


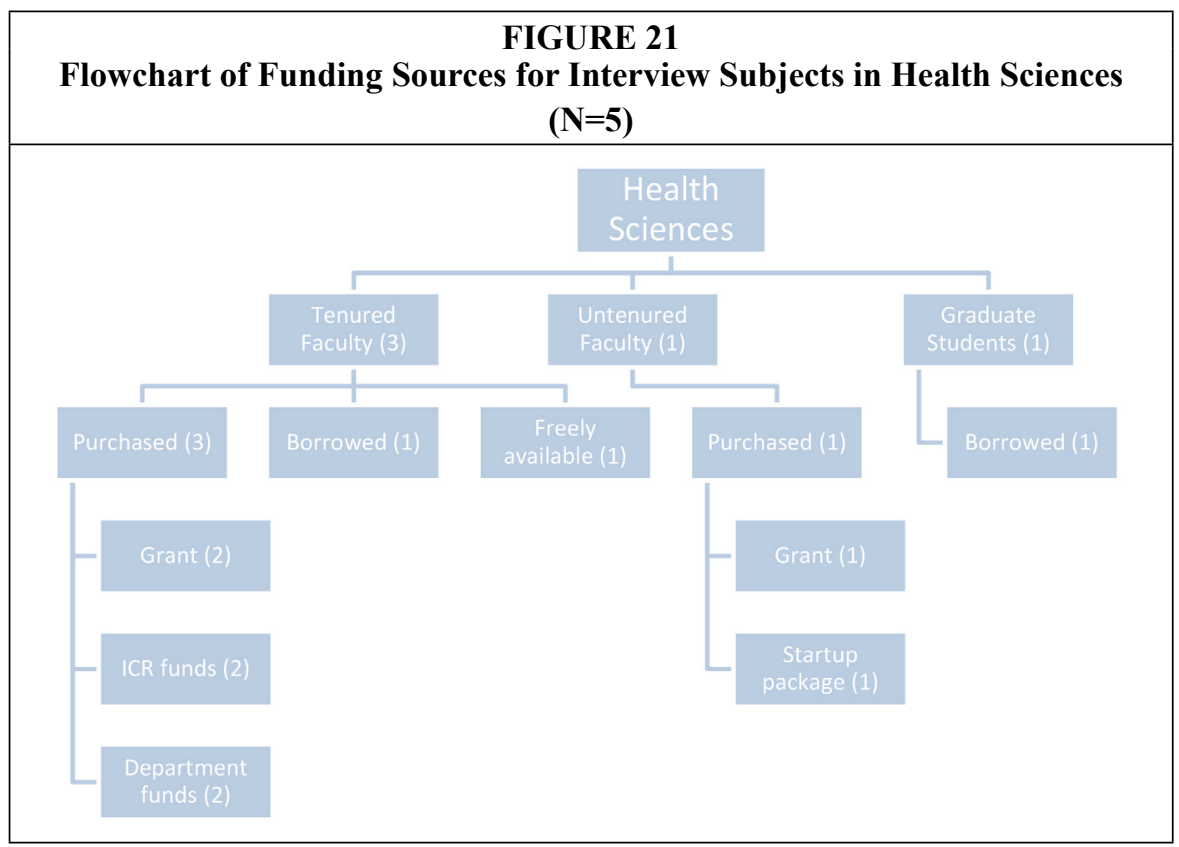

The exploratory nature of this study limits the generalizability of the findings. However, despite being limited to this one research context, the size of the institution and broad range of disciplines and activities covered in this study provide a rich starting point for future research and the development of library services aimed at these types of researchers. Librarians serving game design or game development programs may observe different needs from those identified in this study because UMN does not have a dedicated game design program.

The open-ended, semistructured nature of the interviews resulted in rich and diverse data that posed some problems when categorizing findings and ensuring anonymity. We used broad codes and categories to capture as much data as possible while also maintaining anonymity, resulting in some loss in the granularity of the data. Additionally, determining how to assign disciplines to interviewees to maintain anonymity was challenging. For example, depending on the context, History can be considered a social science or part of the humanities as it is "multifaceted and diffuse." ${ }^{36}$ We chose to place it in arts and humanities because the researchers interviewed were primarily studying video games as cultural objects instead of the impact on society or human behavior.

Finally, some of the subjects discussed were sensitive (for example, institutional barriers to completing work or acquisition of funding) and some participants felt apprehensive about sharing information. Therefore, the data only represents what interviewees shared "on the record." Occasionally, the interview location could have inhibited participants (for example, one interview occurred in a public location and two interviews occurred where interviewees' colleagues were present). However, we have no reason to believe that interviewees concealed information or provided untruthful answers; in the cases where subjects spoke "off the record," they were candid and honest about challenges with their work.

\section{Demographics and Collaboration}

Four disciplines were represented in both the larger population of game scholars and 
our sample of 30 interviewees. All but one interviewee identified strongly with a single area of study, usually the person's department or area of research. No single department or discipline dominated; video games were used institutionwide.

Most interviewees had strong disciplinary ties and also had strong patterns of collaboration outside their departments. Collaboration was common for those we interviewed regardless of discipline. We anticipated a higher frequency of collaboration in STEM and health sciences because previous studies showed high levels of formal collaboration in these disciplines, ${ }^{37}$ but this did not bear out in the interview sample. Collaborative partnerships took the form of coauthorships, collaborative conference presentations, and participation on doctoral committees, as well as many informal collaborations. Informal collaborations were also commonly described by interviewees and included professional friendships, relationships with advisors and committee members, pilot projects, and interest groups.

These data on collaboration are useful to keep in mind while discussing disciplinary trends around information and technology needs. Widespread collaboration on game-related projects and other projects suggests a need for cross-departmental and cross-disciplinary collaboration among librarians on collection development and the creation of services. Some libraries that invested in game technology do serve a range of users and disciplines, ${ }^{38}$ but other prominent collections of games and game technology in academic libraries were driven by the needs of only one or two departments. ${ }^{39}$ Awareness of the collaborative partnerships that exist could help libraries go beyond serving one student, class, or researcher at a time, and investments in game technology have the potential to support the work of whole networks of researchers and instructors. Explicit library support of collaborative work with video games could even give fringe projects and new collaborations a space to intersect and thrive. At UMN there is the potential for many departments and subject librarians to guide the development of a possible video game collection, and this would require a very collaborative approach to collection development.

\section{Academic Use of Video Games: Research and Teaching}

Video games were commonly used in research across all four disciplines represented in our sample. This confirmed a need for the collection development practices of universities such as UChicago ${ }^{40}$ University of Michigan, ${ }^{41}$ and Carleton University, ${ }^{42}$ which accommodated users from multiple disciplines.

We did not anticipate how common video games are in classrooms, since published information about game-related courses only identified a handful of classes at any comparable institution, unless they were focused on game design. Additionally, very few course descriptions in the UMN course catalog mentioned video games, and, of the game-related courses we found during our initial searching, most were in the social sciences or arts and humanities. We did not expect so many STEM and health science classes to integrate games as well. In fact, the use of video games in classes was present within all the disciplines, especially in introductory undergraduate courses and upper level seminars. The course descriptions were often vague enough to give the instructor leeway in how to develop his or her individual section, and those who wished to incorporate games could do so. Some departments even encouraged gamerelated classes due to consistently high enrollment.

Most people in our sample incorporated games into both their research and teaching. We suspect that having a research interest in games may make it more likely for them to incorporate video games into the classroom as well. This may explain why only two people in our sample were using video games exclusively in the classroom. 
Overall, knowing how scholars are using video games and gaming technology on campus formed the backbone of this needs assessment. Any effort to provide library support for video game-related work will impact both research and classroom/student needs. Since we know that most scholars are using games in both research and teaching capacities, the support of this work may have double the impact.

\section{Role of Video Games in Research and Teaching}

There were clear disciplinary trends in the types of research done with video game technology. The development of video games primarily occurred in STEM, while video games were most often used as a text or an object of study in arts and humanities research. There were also some strong similarities among the disciplinary groups. At least one interviewee in every discipline conducted research that studies "educational technology" or "the influences on people and society." Since video games were used by different disciplines in different ways, the type of support the library offers should not be done through the lens of a single department or discipline, and a variety of materials need to be available for many different applications including development, study, and experimental design.

Disciplinary differences were more difficult to discern when examining the role of games in teaching. Many classes were new or were only offered once; even so, teaching game design or designing games from scratch occurred not only in STEM but also in social science and arts and humanities classrooms. Incorporating game technology as course material was common, and interviewees identified a number of different ways in which games were used: readings, storytelling devices, and technology in labs. Students were impacted by these course requirements as well. Many interviewees described accommodations for students who did not own a console or a computer equipped to run graphics-intensive games, but some required students to figure out how to access the games on their own (such as via a personal account on the Steam game distribution system). ${ }^{43}$

Game design was taught in four classes from three disciplines, which was unexpected because there is no game design program or certificate at UMN. Supporting classes that incorporate game design would be easier if they were all in one area of study, but a subject liaison might only be aware of the one class in his or her discipline. Regular environmental scans might be needed to uncover common technology and material requirements for classes across disciplines for courses that use video games and other emerging technologies.

\section{Information Needs}

The most commonly used information sources were Google Scholar, journals, and web sources. The interviewees in the social sciences and arts and humanities were the strongest users of "traditional" library materials such as books and journals. Several interviewees described having to acquire the majority of their texts through interlibrary loan (ILL) because their library did not have the journals or books they needed. Libraries need to review collections in this and other emerging areas to minimize the need for backchannels and shortcuts.

Colleagues were the single most common source of information for interviewees, especially in STEM and health sciences. In one case, a project in health sciences was developed entirely with information and skills contributed from existing relationships. The frequency with which interviewees in this sample collaborate outside their department emphasizes the importance of colleague networks in new and emerging areas. Libraries cross departmental and disciplinary borders and can cultivate a role as a connector for scholars doing similar work in different subject areas with events, experimental technology space, or other strategies. 
Libraries should pursue partnerships with existing video game archives and other libraries or investigate shared collection development efforts to help researchers and the public overcome barriers to accessing game-related information sources. Interview participants identified video games as both a kind of technology and a type of information. Games are available in some academic libraries and public libraries, but it is unclear how accessible they are outside their immediate communities or institutions through ILL. Game manuals and trade magazines like Nintendo Power were also used by several interviewees. Public libraries typically collect trade magazines but, according to Worldcat, many often only keep the last $1-2$ years. Locating game manuals is even more difficult, as they typically lie only in the hands of hobbyists and collectors. A search on Worldcat shows that relatively few libraries have holdings for either game magazines or manuals, raising the question of how libraries can facilitate access to these materials.

The depth and variety of sources used makes it clear that libraries cannot be the sole gatekeepers of information on this subject. The people in our sample used subscription journals but also ephemeral, noncurated materials (such as game manuals, gaming websites, and streaming games). Other library resources like subscription databases were not as valuable for most interviewees, possibly because they are too narrow in scope or interviewees are simply not aware of them. Rather than collect all of the sources scholars need, libraries can create guides to help scholars locate these materials elsewhere, akin to the University of Michigan CVGA LibGuide. ${ }^{44}$

\section{Technology Needs}

Interviewees' needs for devices, displays, and peripherals show no disciplinary trends. Investing in a range of equipment would benefit the largest range of users at UMN. Arts and humanities and social science scholars had a greater need for video games, while those in STEM and health sciences had more software needs. In fact, only one person in STEM identified games as a need, and only one interviewee in arts and humanities used software of any kind.

Disciplinary trends ought to factor into decisions related to purchasing and marketing game technology. For example, at UMN, subject librarians and users in the arts and humanities and social sciences disciplines might be primarily responsible for selecting game titles. Subject librarians for STEM and health sciences should weigh in on video game software selection, since usage would be most expected from STEM and health sciences disciplines.

Among our interviewees, the PC was the most common technology necessary to research and teaching. PCs are necessary to academic work, but there was some nuance to how interviewees used them. PC games are used almost as much as nearly all other types of games combined (console, mobile, and web-based). Mobile games are a growing industry, ${ }^{45}$ but they are not used heavily on this campus for academic purposes. Other technology needs are tied to PC games as well; PC accessories, most often graphics cards, were the third highest need in the equipment category. PC games do not require much additional technology besides a computer (unless a powerful game requires faster processing or graphics cards), so they may be more attractive to the researchers and instructors from arts and humanities and social science, who make up the majority of game users. Guidance on collecting PC games is limited, since few academic libraries currently collect them. Most libraries with game collections and services collect console games almost exclusively, likely because console games do not have restrictive digital rights management (DRM) or require an account to play and are easier to collect and lend.

Peripherals were a common technology need, especially in health sciences. Interviewees shared a diverse range of applications for peripherals that have nothing to do 
with consoles: to control robotics, play PC games, and modify to use as instrumentation. Interviewees also preferred them for their low cost and ability to interface with a number of technologies. Since they are flexible and relatively cheap, libraries and makerspaces could provide a variety of peripherals (with or without consoles) for on-site use or rental.

\section{Acquisition of and Funding for Games and Gaming Technology}

In general, interviewees found they could purchase games or technology at stores or online but did not always have funding to do so. The acquisition of games and video game technology was intrinsically tied to funding, which was mentioned as the largest barrier to acquiring technology.

Graduate students used a variety of creative strategies to acquire technology (such as using their personal game collection, borrowing from friends, and other means), whereas faculty and staff simply purchased technology with grants or other funds as needed or used freely available games and technologies, such as online emulators. Graduate students may have less funding available, or they do not know how to access existing funding. The majority of graduate students, all from the social sciences and arts and humanities, were paying out-of-pocket.

Graduate students had the same technology needs as faculty and staff and conduct their own research, often independent of their faculty advisors and any associated funding. STEM graduate students were the only ones receiving grants or new technology funds. We argue that graduate students would be the primary beneficiaries of having video games and technology available, as this would break down disciplinary acquisition and funding barriers. Underfunded graduate students are probably not unique to UMN; and, if libraries made these games and technologies available, graduate students would have much more flexibility in their research. The arts and humanities students who purchased video games out-of-pocket likely used the games as primary research materials, analogous to texts. Since many libraries purchase books for research, it should be easy to purchase games for analogous reasons.

Libraries can also help connect graduate students with funding. Many academic units at UMN provide grants to fund graduate research, and the UMN Libraries subscribe to grant databases and offer workshops on locating grant funding. Since graduate student research is highly valued, it makes sense to assist them in their efforts to acquire game technology by building their grant-seeking skills.

Even though faculty and staff theoretically have the same opportunities for funding, untenured faculty and staff seek more sources of funding to meet their needs, whereas tenured faculty receive most of their funding from grants. Startup packages supported three untenured faculty from STEM and the health sciences, and one staff member reported having to pay out-of-pocket to buy games for classroom use. Faculty and staff for the most part were successful in finding funding to purchase the required technology, but making materials available at the library would put less pressure on faculty and staff to acquire them in other ways and would give them an option to use their funding for other purposes.

Collections in the UMN Libraries are focused primarily on meeting faculty research and teaching needs, as faculty tend to stay at the university longer than students. We recognize that these data could suggest that faculty and staff do not have many barriers to accessing technology and that it is neither necessary nor urgent to include video games and video game technology in library collections. It could also be argued that grants and other funding sources already pay for research and classroom needs and that libraries are not in the business of directly funding research costs like instrumentation, experimental design, or technology development. However, many faculty we spoke 
to welcomed a chance to collaborate with librarians whether or not the library could directly support their research. Some faculty incorporate games into their outreach service, and many have classes that would benefit from the availability of game materials. We also argue that libraries have a great opportunity to engage with graduate and undergraduate students who want to experiment with games before personally investing in the technology.

By focusing our study on researchers and instructors, we have missed the opportunity to explore implications for students taking classes that incorporate games and gaming technology. What we know came solely from the instructors' viewpoints; therefore, we do not have a comprehensive picture of how these technologies were made available to students or if they encountered barriers to accessing them. In some classes the game technology was provided, like a health sciences class where Wii balance boards were available to take measurements; but, in another case, students were expected to purchase World of Warcraft and install it on their PCs. Some instructors did note that requiring students to purchase video games may be prohibitive and not directly analogous to purchasing textbooks, as it requires students to own consoles or a high-powered PC that supports gaming. Some attempted to find alternative solutions such as asking the UMN Libraries to install games on library computers and investigating Steam licensing for computer labs. It would be worthwhile to interview students from some of these classes to uncover if they encountered any barriers in attempting to access these technologies.

\section{Conclusion}

There is little data available about the information and technology needs of researchers and instructors who use video games in higher education. This study attempted to fill that gap with interviews with faculty, staff, and graduate students from UMN. Scholars from all disciplinary groups were represented and demonstrated both a high level of collaborative activity and use of video games in both research and teaching. As libraries build new video game collections or expand existing collections, they should consider the following findings:

- Information used in game-related research and teaching includes nontraditional material such as trade magazines and game manuals. Journals were the most common source of information identified overall, but some essential titles may not be collected or indexed in library catalogs.

- Video games are most often researched as an influence on society and having a role in educational technology. This research is diverse and may have vastly different needs.

- Video games are commonly used as course material in courses from all disciplines, but console games may not be used as frequently as PC games.

- All of the interviewees needed game-related technology, though there was much variation among the disciplines: arts and humanities and social sciences required video games; STEM required software; health sciences required peripherals.

- Graduate students, especially those from arts and humanities, are at a major funding disadvantage compared to colleagues in the sciences. This impedes access to game technology required for research and teaching and often requires them to pay out-of-pocket.

This study found some consistency in video game applications between disciplines but even more differences, especially in technology and information use. This suggests that the support libraries provide should be done collaboratively through a multidisciplinary lens. We propose a strategic approach to video game services and collections focused on disciplinary needs. For UMN, this would mean building a collection fo- 
cused on PC games, a few console games, cutting-edge equipment with game design software, and a collection of peripherals with or without consoles, perhaps associated with a makerspace. Each academic game collection should reflect its institution, based on an evaluation of the unique needs of its population.

Since this study was limited to the UMN campus, we would like to see similar studies undertaken at various institutions that look at how students use and acquire games for classroom use, as well as a large-scale multi-institution look at the use of games in higher education. As technology changes and moves away from physical media, academic institutions will benefit from studies looking at the impact of DRM on scholarship and libraries. Very few video game companies have partnerships with higher education, and more exploration of this issue is needed. These studies would provide a more complete understanding of scholarly video games-related work and scholars' information and technology needs. 


\section{APPENDIX. Interview Themes, Codes, and Definitions}

1. Academic status

口 Graduate student: both master's and doctoral students

$\square \quad$ Untenured faculty and staff: assistant professor, instructor, postdoc

2. Discipline

$\square \quad$ Tenured faculty: associate professor, full professor

$\square \quad$ Arts and Humanities: includes any field where the human experience and expressions or explanations thereof are the primary objects of study. History is included here because the interviewees study video games and texts and consider the games as the object of study

$\square \quad$ Health Sciences: medical, kinesiology, and related disciplines

$\square \quad$ Social Sciences: includes any field where humans are the primary object of study

STEM: includes disciplines from science, technology, engineering, and mathematics

3. Are they collaborating with other disciplines?

$\square \quad$ Yes

$\square \quad$ No

4. Are their collaborations with other disciplines formal, informal, or both?

․ Formal collaborations: working on a project, publishing a paper, working on a grant together, serving as an academic advisor or member of a thesis or dissertation committee

$\square \quad$ Informal collaborations: talking to/with people, sharing ideas

Both: a combination of both formal and informal collaborations

5. How many collaborations do they currently have outside of their department?

$\square \quad$ Intradepartmental: work alone or only collaborate within their own department

․ Interdepartmental (1-2): between 1-2 collaborations outside their own department

․ Interdepartmental (3+): 3+ collaborations outside their own department or split positions between departments

6. Have they used video games or gaming technology in their research?

$\square \quad$ Yes

․ No

7. How do they use video games or games technology in their research?

$\square$ Development of games/technology: researcher has created the video game or associated technology

․ Instrumentation: using video games to gather quantitative data

$\square \quad$ Object of study: using critical analysis or thematic study of video games

$\square \quad$ Influences on people or society: researcher is examining the societal impact of video games

$\square \quad$ Educational technology: using video games to facilitate learning and improve student outcomes

8. Have they used video games or gaming technology in their teaching?

$\square \quad$ Yes

$\square \quad$ No

9. In what classes are you using video games or gaming technology?

$\square \quad$ Undergraduate: lower-level classes, primarily for those pursuing their bachelor's (1xxx-4xxx) 
$\square \quad$ Graduate: upper level classes, marketed toward master's and doctoral students (5xxx-8xxx)

10. How do they use video games or games technology in the classroom?

$\square \quad$ Instructor designed a game: instructor created a video game for use in the classroom

- Taught game design: instructor taught students how to design their own games

$\square \quad$ Used games as course material: video games were studied in the classroom, as primary sources

$\square \quad$ Discussed games: video games were used in the classroom as secondary sources

$\square \quad$ Other: any other response that did not fall within the above categories

11. How do they acquire games or gaming technology?

$\square$ Borrowed/given: the material was owned by someone else and the researcher or instructor acquired from them

$\square \quad$ Purchased: the material had to be purchased by the researcher or instructor either out-of-pocket or with other funds

$\square \quad$ Already owned: the instructor or researcher previously owned the material

$\square \quad$ Freely available: available at no cost to consumers

$\square \quad$ Other: any other response that did not fall within the above categories

12. Did they have funding for their research or teaching?

$\quad$ Grant (general): acquired funding via another organization to pursue their research or teaching projects

$\square \quad$ New technology funds: funds provided for the explicit purpose of acquiring new technologies

$\square \quad$ Seed grant: initial capital to start a project

$\square \quad$ Department funds: funding provided by researcher's or instructor's department

$\square \quad$ Dissertation fund: funding provided by graduate student's department or graduate school to support dissertation research

$\square \quad$ Startup package: new professor was provided with funding to set up a lab

$\square \quad$ Indirect cost recovery (ICR) funds: funds that the university collects to cover overhead costs when grants are written. A portion is returned back to departments

$\square \quad$ Out-of-pocket: the instructor or researcher had to use personal money to cover the cost

$\square \quad$ MNDrive grant: grant allocated via partnership between the UMN and the state of Minnesota that provides funding in areas of interdisciplinary research that align with specific industries

$\square \quad$ Not required: no funding was required for this research or teaching

13. What are your technology needs?

․ Equipment, console: consoles, such as Xbox 360, Xbox One, PS3, PS4, Wii, WiiU, or any other

$\square \quad$ Equipment, controllers, and peripherals: secondary equipment for the gaming systems listed above, including controllers, Wiimotes, headsets, Xbox Kinects, Wii balance boards, steering wheels, and the like

$\square \quad$ Equipment, mobile: smartphones, tablets, and other mobile devices, including iPhones, iPads, and such

Equipment, display: equipment used to view video games, including television screens, computer monitors, or any other display equipment

$\square \quad$ Equipment, personal computer: includes Mac, Windows, and Linux systems 
$\square \quad$ Equipment, personal computer accessories: secondary equipment for PC gaming, including joysticks, controllers, headsets, webcams, and other equipment

Games, web: games that are available through a browser or browser-based emulator, or for download online

$\square \quad$ Games, PC: games purchased to play on personal computers

Games, console: games purchased to play on consoles

$\square \quad$ Games, mobile: games that are available on smartphones or tablets

Programming languages: computer language used to communicate instructions to a machine, including $\mathrm{C}, \mathrm{C}++$, Java, Javascript, Python, and other languages

- Servers: computers or programs that manages access to a network resource

$\square \quad$ Software, proprietary: software that must be purchased from the individual or company that developed it; often includes major restrictions for adaptation and use

$\square \quad$ Software, free or open source: software that is available for free, typically on the web; often allows users to modify or adapt as needed

$\square$ Software, custom: software written by the researcher or instructor from scratch

$\square \quad$ Software, game design: software developed for the specific purpose to design video games

․ Web applications: software application that is available and runs on the web, such as streaming video

14. Where are they finding information?

$\begin{array}{cl}\square & \text { Archives: historical documents or records } \\ \square & \text { Books: written or printed works } \\ \square & \text { Colleagues: talking to people in their discipline } \\ \square & \text { Conferences: formal meetings for people in related disciplines } \\ \square & \text { Course readings: resources that were provided while taking a class } \\ \square & \text { Datasets: collection of related sets of information } \\ \square & \text { Game manuals: instructions on how to play video games } \\ \square & \text { Game reviews: evaluations of video games } \\ \square & \text { Games: console, PC, mobile, or web video games } \\ \square \quad \text { Google Scholar: freely accessible web search engine that indexes scholarly } \\ \square \quad \text { literature } \\ \square \quad \text { Journals: collections of articles about specific subjects or disciplines } \\ \square \quad \text { Library databases: catalog of both full-text resources and indexed citations } \\ \quad \text { that are accessible electronically } \\ \square \quad \text { Newsletters: bulletins that are issued periodically } \\ \square \quad \text { News sources: includes both print and website-based news } \\ \square \quad \text { Students: people enrolled in either undergraduate or graduate programs } \\ \square \quad \text { Trade magazines: periodicals that contain news and items about a par- } \\ \quad \text { ticular topic } \\ \square \quad \text { Web sources: materials found on the open web } \\ \square \quad \text { Other: any other response that did not fall within the above categories }\end{array}$

\section{Notes}

1. Meave Duggan, "Gaming and Gamers" (Report, Pew Research Center, 2015), available online at www.pewinternet.org/2015/12/15/gaming-and-gamers/ [accessed 18 December 2015]. 
2. Laurence F. Johnson et al., "NMC Horizon Report: 2015 Higher Education Edition," Horizon Report (Austin, Tex.: The New Media Consortium, 2015), 22, 35, available online at www.nmc.org/ publication/nmc-horizon-report-2015-higher-education-edition/ [accessed 18 December 2015].

3. Association of College and Research Libraries, "ACRL Plan for Excellence," 2015, available online at www.ala.org/acrl/aboutacrl/strategicplan/stratplan [accessed 11 January 2016].

4. Brena Smith, "Twenty-First Century Game Studies in the Academy: Libraries and an Emerging Discipline," Reference Services Review 36, no. 2 (2008): 205-20, doi:10.1108/00907320810873066.

5. Examples include Mary Laskowski and David Ward, "Building Next Generation Video Game Collections in Academic Libraries," Journal of Academic Librarianship 35, no. 3 (May 2009): 267-73, doi:10.1016/j.acalib.2009.03.005; Kristen Mastel and Dave Huston, “Using Video Games to Teach Game Design: A Gaming Collection for Libraries," Computers in Libraries 29, no. 3 (2009): 41-44, available online at http://eric.ed.gov/?id=EJ831241 [accessed 18 December 2015]; and Diane Robson and Patrick Durkee, "New Directions for Academic Video Game Collections: Strategies for Acquiring, Supporting, and Managing Online Materials," Journal of Academic Librarianship 38, no. 2 (Mar. 2012): 79-84, doi:10.1016/j.acalib.2012.01.003.

6. Examples include Natalie Gick, "Making Book: Gaming in the Library: A Case Study," in Gaming in Academic Libraries: Collections, Marketing, and Information Literacy (Chicago: American Library Association, 2008), 1-25; David Baker et al., "Lessons Learned from Starting a Circulating Videogame Collection at an Academic Library," in Gaming in Academic Libraries: Collections, Marketing, and Information Literacy (Chicago: American Library Association, 2008), 26-38; Danielle Kane, Catherine Soehner, and Wei Wei, "Building a Collection of Video Games in Support of a Newly Created Degree Program at the University of California, Santa Cruz," Science \& Technology Libraries 27, no. 4 (Aug. 20, 2007): 77-87, doi:10.1300/J122v27n04_06; and Emma Cross, David Mould, and Robert Smith, "The Protean Challenge of Game Collections at Academic Libraries," New Review of Academic Librarianship 21, no. 2 (May 4, 2015): 129-45, doi:10.1080/13614533.2015.1043467.

7. Mary Laskowski and David Ward, "Building Next Generation Video Game Collections in Academic Libraries," Journal of Academic Librarianship 35, no. 3 (May 2009): 267-73, doi:10.1016/j. acalib.2009.03.005.

8. Andy Burkhardt, "Taking Games in Libraries Seriously," The Academic Commons (blog), available online at www.academiccommons.org/2014/07/24/taking-games-in-libraries-seriously/ [accessed 5 November 2015].

9. Chris Nelson, "Gaming Reaches into Far Corners of Academic World as U of C Builds Huge Collection," Calgary Herald (Mar. 16, 2015), available online at http://calgaryherald.com/news/ local-news/gaming-reaches-into-far-corners-of-academic-world-as-u-of-c-builds-huge-collection [accessed 4 November 2015].

10. Brian McNeill, "VCU Libraries Launches Collection of Critically Acclaimed Video Games," VCU News (blog) (Nov. 6, 2014), available online at http://news.vcu.edu/article/VCU_Libraries_launches_collection_of_critically_acclaimed_video [accessed 4 November 2015].

11. Sarah G. Wenzel, "New Library Videogame Collection," The University of Chicago Library News (blog) (May 25, 2012), available online at http://news.lib.uchicago.edu/blog/2012/05/25/ new-library-videogame-collection/ [accessed 30 November 2015].

12. Patrick Jagoda, "Videogame Collection Supports Scholarly Study," The University of Chicago Library News (blog) (May 25, 2012), available online at http://news.lib.uchicago.edu/ blog/2012/05/25/videogame-collection-supports-scholarly-study/ [accessed 30 November 2015].

13. An overview of classes and disciplinary uses is discussed in Mary Claire Morris, "Computer \& Video Game Archive Celebrating Five Years of Growth," The University Record (blog) (Nov. 5, 2013), available online at http://record.umich.edu//articles/computer-video-game-archivecelebrating-five-years-growth [accessed 2 December 2015]. A list of classes and research applications can be found in Valerie Waldron, "Computer \& Video Game Archive: CVGA," University of Michigan Research Guides (2015), available online at http://guides.lib.umich.edu/c.php?g=282987 [accessed 2 December 2015].

14. Emma Cross, David Mould, and Robert Smith, "The Protean Challenge of Game Collections at Academic Libraries," New Review of Academic Librarianship 21, no. 2 (May 4, 2015): 135-37, doi:10.1080/13614533.2015.1043467.

15. David Ward, "Vintage Gaming Collection Development Policy and Description" (Urbana, Ill.: University of Illinois Urbana-Champaign, 2014), available online at www.library.illinois.edu/ gaming/gamearchives.html [accessed 20 December 2015].

16. Valerie Waldron, "Computer \& Video Game Archive: CVGA," University of Michigan Research Guides (2015), available online at http://guides.lib.umich.edu/c.php?g=282987 [accessed 2 December 2015]

17. University of California Santa Cruz Library, "Video Games" (2015), available online at https://library.ucsc.edu/collections/video-games [accessed 18 December 2015].

18. Diane Robson and Patrick Durkee, "New Directions for Academic Video Game Collec- 
tions: Strategies for Acquiring, Supporting, and Managing Online Materials," Journal of Academic Librarianship 38, no. 2 (Mar. 2012): 82, doi:10.1016/j.acalib.2012.01.003.

19. Cross, Mould, and Smith, "The Protean Challenge of Game Collections," 134.

20. McNeill, "VCU Libraries Launches Collection."

21. Jagoda, "Videogame Collection Supports Scholarly Study."

22. Adam DePollo, "Play On: Changing Gamer Culture at the 'U,'” Michigan Daily (Oct. 22, 2014), available online at https://www.michigandaily.com/arts/10computer-video-game-archive22 [accessed 2 December 2015].

23. Laskowski and Ward, "Building next Generation Video Game Collections," 268.

24. McNeill, "VCU Libraries Launches Collection."

25. Jagoda, "Videogame Collection Supports Scholarly Study."

26. University of Calgary Libraries and Cultural Resources, "Video Games," available online at http://library.ucalgary.ca/dmc/video-games [accessed 4 November 2015].

27. Emma Cross and Robert Smith, "The Evolution of Gaming at Academic Libraries," Canadian Library Association Conference (Winnepeg, Manitoba, 2013), available online at https://prezi.com/ supsungb2uil/the-evolution-of-gaming-at-academic-libraries/ [accessed 4 November 2015].

28. Burkhardt, "Taking Games in Libraries Seriously."

29. Three examples of soliciting direct feedback from faculty and students are found in Kane, Soehner, and Wei, "Building a Collection of Video Games"; Laskowski and Ward, "Building Next Generation Video Game Collections"; and Cross, Mould, and Smith, "The Protean Challenge of Game Collections."

30. Nelson, "Gaming Reaches into Far Corners of Academic World."

31. DePollo, "Play On: Changing Gamer Culture at the 'U.'”

32. Laskowski and Ward, "Building Next Generation Video Game Collections," 268.

33. Cross, Mould, and Smith, "The Protean Challenge of Game Collections," 133.

34. Jagoda, "Videogame Collection Supports Scholarly Study."

35. Waldron, "Computer \& Video Game Archive."

36. Mark T. Gilderhus, History and Historians : A Historiographical Introduction, 7th ed. (Englewood Cliffs, N.J.: Prentice Hall, 2010), 41.

37. Vincent Larivière, Yves Gingras, and Éric Archambault, "Canadian Collaboration Networks: A Comparative Analysis of the Natural Sciences, Social Sciences and the Humanities," Scientometrics 68, no. 3 (2006): 519-33, doi:10.1007/s11192-006-0127-8.

38. Nelson, "Gaming Reaches into Far Corners of Academic World."

39. Kane, Soehner, and Wei, "Building a Collection of Video Games."

40. Wenzel, "New Library Videogame Collection."

41. Mary Claire Morris, "Computer \& Video Game Archive Celebrating Five Years of Growth," The University Record (blog) (Nov. 5, 2013), available online at http://record.umich.edu//articles/ computer-video-game-archive-celebrating-five-years-growth [accessed 2 December 2015].

42. Cross, Mould, and Smith, "The Protean Challenge of Game Collections," 144.

43. For more information, see http://store.steampowered.com/about/.

44. Waldron, "Computer \& Video Game Archive."

45. John Gaudiosi, "Mobile Game Revenues Set to Overtake Console Games in 2015," Fortune, (Jan. 15, 2015), available online at http://fortune.com/2015/01/15/mobile-console-gamerevenues-2015/ [accessed 15 January 2016]. 